\title{
Monomethylated and unmethylated FUS exhibit increased binding to Transportin and distinguish FTLD-FUS from ALS-FUS
}

\author{
Marc Suárez-Calvet ${ }^{1,7,9} \cdot$ Manuela Neumann ${ }^{3,4}$ - Thomas Arzberger ${ }^{5,6,7}$. \\ Claudia Abou-Ajram ${ }^{1,2}$ • Eva Funk ${ }^{1}$ - Hannelore Hartmann ${ }^{7,8}$ • Dieter Edbauer ${ }^{7,8}$. \\ Elisabeth Kremmer ${ }^{10}$ - Christoph Göbl ${ }^{11,12}$ • Moritz Resch ${ }^{11,12}$. \\ Benjamin Bourgeois ${ }^{11,12}$ - Tobias Madl ${ }^{11,12,13,14} \cdot$ Stefan Reber $^{15,16}$. \\ Daniel Jutzi $^{15}$ - Marc-David Ruepp ${ }^{15}$ - Ian R. A. Mackenzie ${ }^{17}$ - Olaf Ansorge ${ }^{18}$. \\ Dorothee Dormann ${ }^{1,2,8} \cdot$ Christian Haass ${ }^{1,7,8}$
}

Received: 31 July 2015 / Revised: 29 January 2016 / Accepted: 29 January 2016

(C) Springer-Verlag Berlin Heidelberg 2016

\begin{abstract}
Deposition of the nuclear DNA/RNA-binding protein Fused in sarcoma (FUS) in cytosolic inclusions is a common hallmark of some cases of frontotemporal lobar degeneration (FTLD-FUS) and amyotrophic lateral sclerosis (ALS-FUS). Whether both diseases also share common pathological mechanisms is currently unclear. Based on our
\end{abstract}

Electronic supplementary material The online version of this article (doi:10.1007/s00401-016-1544-2) contains supplementary material, which is available to authorized users.

Dorothee Dormann

dorothee.dormann@med.uni-muenchen.de

$\checkmark$ Christian Haass

christian.haass@mail03.med.uni-muenchen.de

1 Biomedical Center (BMC), Biochemistry, LudwigMaximilians-University Munich, Feodor-Lynen Strasse 17 81377 Munich, Germany

2 Present Address: BioMedical Center (BMC), Lehrstuhl Zellbiologie (Anatomie III), Großhaderner Strasse 9, 82152 Planegg-Martinsried, Germany

3 Department of Neuropathology, University of Tübingen, 72076 Tübingen, Germany

4 DZNE, German Center for Neurodegenerative Diseases, 72076 Tübingen, Germany

5 Department of Psychiatry and Psychotherapy, LudwigMaximilians-University Munich, 80336 Munich, Germany

6 Center for Neuropathology and Prion Research, LudwigMaximilians-University Munich, 81377 Munich, Germany

7 German Center for Neurodegenerative Diseases (DZNE) Munich, Feodor-Lynen Strasse 17, 81377 Munich, Germany

8 Munich Cluster for Systems Neurology (SyNergy), 81377 Munich, Germany previous finding that FUS deposits are hypomethylated in FTLD-FUS but not in ALS-FUS, we have now investigated whether genetic or pharmacological inactivation of Protein arginine methyltransferase 1 (PRMT1) activity results in unmethylated FUS or in alternatively methylated forms of FUS. To do so, we generated FUS-specific monoclonal antibodies that specifically recognize unmethylated arginine (UMA), monomethylated arginine (MMA) or asymmetrically dimethylated arginine (ADMA). Loss of PRMT1 indeed not only results in an increase of UMA FUS and a

9 Universitat Autònoma de Barcelona, 08193 Bellaterra, Barcelona, Spain

10 Institute of Molecular Immunology, Helmholtz Zentrum München, German Research Center for Environmental Health $(\mathrm{GmbH}), 81377$ Munich, Germany

11 Department of Chemistry, Center for Integrated Protein Science Munich (CIPSM), Technische Universität München, Lichtenbergstr.4, 85747 Garching, Germany

12 Institute of Structural Biology, Helmholtz Zentrum München, 85764 Neuherberg, Germany

13 Institute of Molecular Biology and Biochemistry, Center of Molecular Medicine, Medical University of Graz, 8010 Graz, Austria

14 Omics Center Graz, BioTechMed, 8010 Graz, Austria

15 Department of Chemistry and Biochemistry, University of Bern, 3012 Bern, Switzerland

16 Graduate School for Cellular and Biomedical Sciences, University of Bern, 3012 Bern, Switzerland

17 Department of Pathology, Vancouver General Hospital, University of British Columbia, Vancouver, Canada

18 Department of Neuropathology, John Radcliffe Hospital, Oxford, UK 
decrease of ADMA FUS, but also in a significant increase of MMA FUS. Compared to ADMA FUS, UMA and MMA FUS exhibit much higher binding affinities to Transportin-1, the nuclear import receptor of FUS, as measured by pulldown assays and isothermal titration calorimetry. Moreover, we show that MMA FUS occurs exclusively in FTLD-FUS, but not in ALS-FUS. Our findings therefore provide additional evidence that FTLD-FUS and ALS-FUS are caused by distinct disease mechanisms although both share FUS deposits as a common denominator.

Keywords Frontotemporal lobar degeneration (FTLD) . Amyotrophic lateral sclerosis (ALS) $\cdot$ Fused in sarcoma (FUS) - Arginine methylation · Neurodegeneration · Protein arginine methyltransferase 1 (PRMT1) · Transportin-1

\section{Introduction}

Fused in sarcoma (FUS) is a nuclear DNA/RNA-binding protein that is the pathological hallmark protein in abnormal cytoplasmic and nuclear inclusions in some cases of frontotemporal lobar degeneration (FTLD) and amyotrophic lateral sclerosis (ALS) [24, 32, 35, 36, 54]. FTLD is the second most common early-onset dementia after Alzheimer's disease (AD) and is clinically characterized by varying degrees of behavioural disturbances, personality changes and language impairment [33]. The neuropathology of FTLD is classified according to the protein deposited in the central nervous system. FTLD cases show pathological deposition of either TAR DNA-binding protein of $43 \mathrm{kDa}$ (TDP-43) [37], microtubule associated protein tau (Tau) [10] or Fused in sarcoma (FUS) [32, 35, 36], hence they are classified as FTLD-TDP, FTLD-Tau or FTLDFUS [30]. Only very rare FTLD cases cannot be classified in these categories, including familial FTLD linked to chromosome 3 (FTD-3) $[17,18]$ (caused by mutations in the $C H M P 2 B$ gene) and FTLD cases with no inclusions (FTLD-ni) [30]. FTLD-FUS represents about $10 \%$ of all FTLD cases [31] and comprises three distinct pathological subtypes, namely atypical FTLD-U (aFTLD-U) [35], neuronal intermediate filament inclusion disease (NIFID) [36] and basophilic inclusion body disease (BIBD) [32]. Genetic and neuropathological analyses revealed overlapping disease characteristics of ALS and FTLD [49]. Although TDP43 is the most common protein underlying ALS pathology, some rare ALS cases are associated with FUS mutations and show instead FUS aggregates (ALS-FUS) [24, 54].

Whether FTLD-FUS and ALS-FUS represent a pathological continuum or distinct diseases remains to be elucidated. Even though they share FUS deposition as the common denominator, there are also several obvious
Fig. 1 Characterization of monoclonal antibodies specific for UMA and MMA FUS. a Schematic figure of the FUS protein. FUS contains multiple functional domains: a QGSY-rich transcriptional activation domain (glutamine, glycine, serine and tyrosine rich domain), three RGG domains (arginine-glycine-glycine repeats); a RRM domain (RNA recognition motif), a $\mathrm{ZnF}$ domain (zinc finger domain), and the PY-NLS (proline-tyrosine nuclear localization signal). We generated antibodies against the differently methylated RGG3 domain $\left(\mathrm{FUS}_{473-503}\right)$ with all nine arginines in three different forms of methylation modifications: UMA (red), MMA (blue) or ADMA (green). An asterisk indicates a methyl group. b Schematic representation of arginine methylation steps. All PRMTs (type I, II and III) are capable to add a methyl group and generate a monomethylated arginine (MMA). Subsequently, type I PRMTs deposit the asymmetrically dimethylated arginine (ADMA) signature, whereas type II PRMTs deposit the symmetrically dimethylated ariginine (SMDA) signature. Type III PRMT (PRMT7) can only generate MMA. c HeLa cells were transfected with siRNAs against FUS, EWS, TAF-15 or a non-targeting control and were subsequently treated with AdOx or left untreated. $48 \mathrm{~h}$ post-transfection cell lysates were analysed by immunoblotting with the antibodies raised against UMA FUS (14G1), MMA FUS (15E11) and ADMA (9G6). All of them show a signal at the predicted molecular weight of FUS (arrow) that disappears upon knockdown of FUS. Whereas ADMA FUS antibody (9G6) shows immunoreactivity to untreated cells, UMA FUS (14G1) and MMA FUS (15E11) antibodies only reacted with lysates derived from AdOx-treated cells. These antibodies do not show cross-reactivity against EWS and TAF-15. Tubulin was used as a loading control and FUS, EWS and TAF-15 antibodies were used to examine knockdown efficiency. Asterisks: unspecific bands

differences between the two disorders. First, ALS cases with FUS pathology are caused by mutations in the FUS gene $[24,54]$. The mutations are predominantly located in or near the proline-tyrosine nuclear localization signal (PYNLS) (Fig. 1a). We and others have previously shown that these mutations disrupt the nuclear import of FUS via the nuclear import receptor Transportin-1 (TRN) and are causally related to pathogenesis of the disease $[14,20,22,39$, 55, 59]. In contrast, no FUS gene mutations were found in FTLD-FUS, except for some rare cases that presented with both FTLD and ALS [25], and in which no pathological descriptions are available and the mutations are not in the C-terminal region of FUS. Second, in contrast to ALS-FUS, cytoplasmic inclusions in FTLD-FUS also contain TRN [5, 38, 53] as well as TAF-15 and EWS, two homologues of FUS that belong to the same protein family (FET family) [34]. Third, we have shown previously that the inclusions in ALS-FUS contain asymmetrically arginine dimethylated (ADMA) FUS [13]. This post-translational modification of FUS reduces its binding to TRN and thus impairs import of mutant FUS into the nucleus [13, 52]. In contrast, FUS deposited in FTLD-FUS cases is not asymmetrically arginine dimethylated [13]. However, it is not yet known whether FUS in FTLD-FUS inclusions is unmethylated or shows an alternative methylation pattern that differs from that found in ALS-FUS or healthy controls. 
a

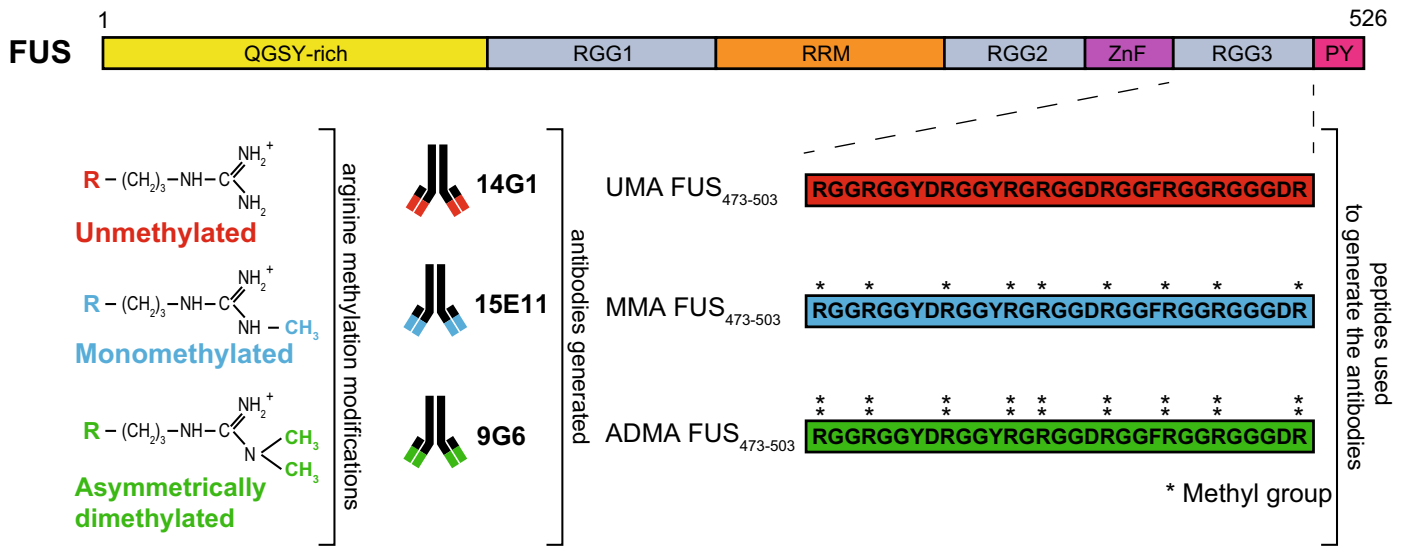

b

$$
\bigwedge_{\text {Unmethylated arginine (UMA) }}^{\mathrm{R}-\left(\mathrm{CH}_{2}\right)_{3}-\mathrm{NH}-\mathrm{C}_{\mathrm{NH}_{2}}^{\mathrm{NH}_{2}^{+}}}
$$

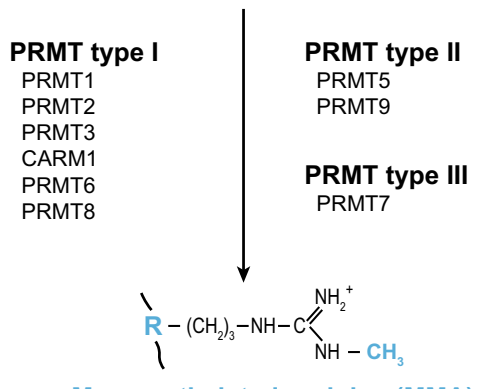

Monomethylated arginine (MMA)

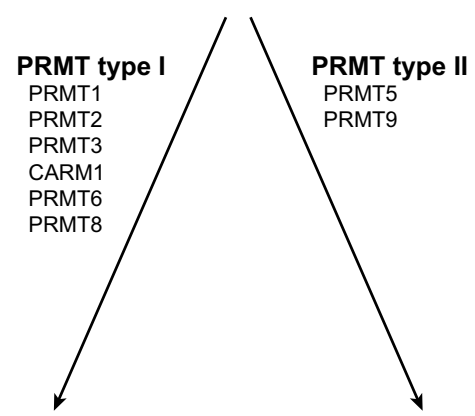<smiles>CN(C)C(=N)NCP(C)C</smiles>

Asymmetrically dimethylated arginine (ADMA)

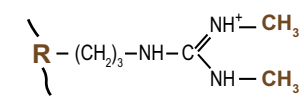

Symmetrically dimethylated arginine (SDMA)

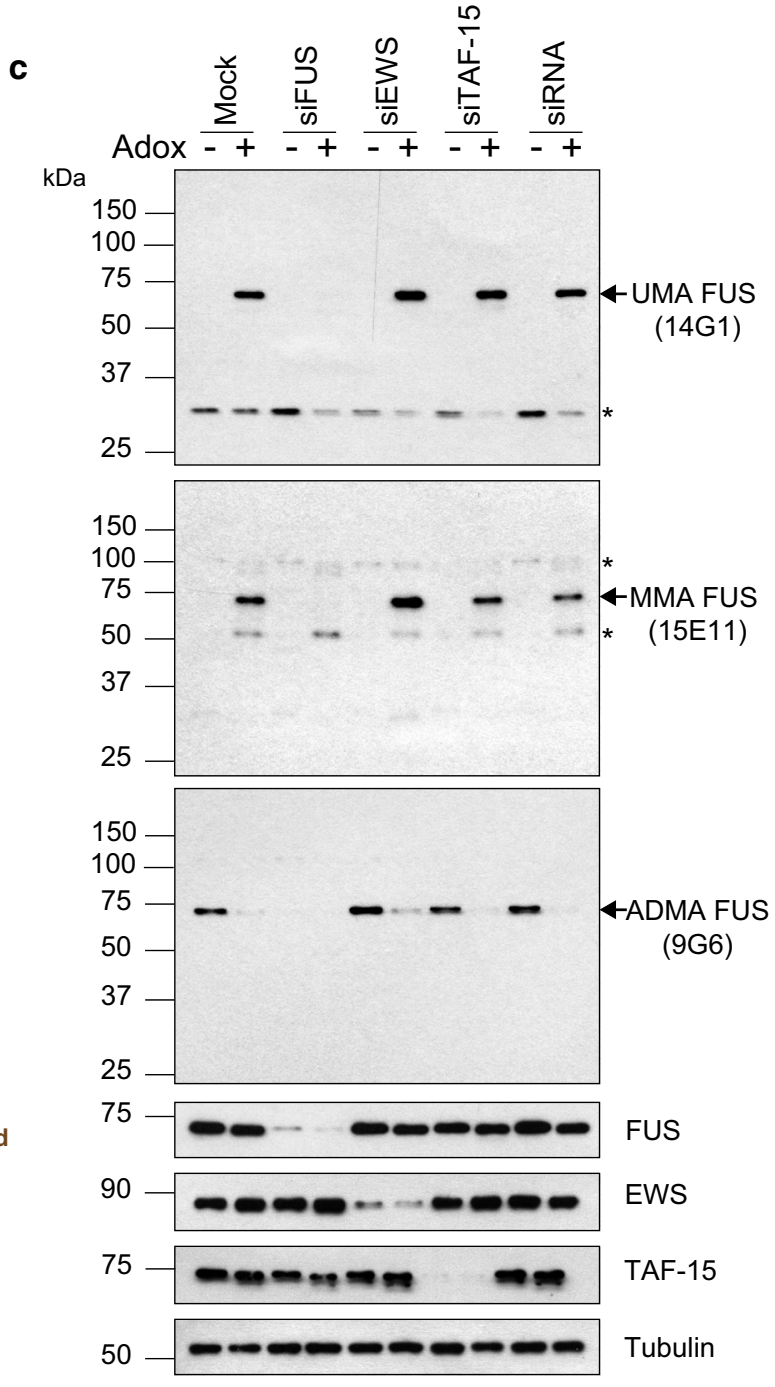

to a dimethylated form that can occur either as ADMA or symmetric $N, N$-dimethylarginine (SDMA) [2, 57]. In mammalian cells, there are nine PRMTs that all catalyse the first step that generates the MMA form, but different PRMTs are responsible for the second step (Fig. 1b). Type I PRMTs

(MMA). Subsequent addition of a second methyl group leads 
(which include PRMT1, PRMT2, PRMT3, PRMT4/CARM1, PRMT6 and PRMT8) mediate asymmetric arginine dimethylation. PRMT1 is the main type I PRMT and is responsible for $90 \%$ of all ADMA enzyme activity in mammalian cells [50]. In contrast, type II PRMTs (PRMT5 and PRMT9) are responsible for SDMA $[2,57]$. Finally, it has been described that PRMT7 exclusively catalyses the generation of MMA and is accordingly classified as a type III PRMT [60]. The MMA form has long been considered to be an intermediate form between the unmethylated arginine (UMA) and ADMA/ SDMA forms. However, recently it has been shown that levels of MMA proteins increase after loss of PRMT1 [9] and that the increase of MMA is not coupled with a subsequent increase in ADMA modifications [48]. These findings suggest that MMA is not just an intermediate form, but may have selective biological functions. PRMTs mostly target arginines in regions rich in glycines and arginines [51]. Proteins of the FET family (FUS, EWS and TAF-15) contain three arginineglycine-glycine (RGG) domains that are thought to mainly undergo asymmetric dimethylation by PRMT1 [1, 4, 19, 21, 43 , 46], i.e. all three proteins appear to be present mainly in the ADMA form under physiological conditions. Some MMA sites have also been reported for the FET proteins [16, 48], whereas there is no evidence of symmetric dimethylation in FET proteins [46].

In the present study, we aimed at characterizing the methylation pattern of FUS in the pathological inclusions in brains of FTLD-FUS patients. To do so, we developed novel monoclonal antibodies specific for the UMA or MMA RGG3 domain of FUS. By using these antibodies along with a previously developed antibody specific to the ADMA RGG3 domain of FUS [13], we show that genetic or pharmacological inhibition of PRMT1 not only results in UMA FUS, but also in alternatively methylated MMA FUS. Moreover, we demonstrate that MMA FUS exhibits increased binding affinities to Transportin-1 similar to UMA FUS, whereas ADMA FUS only binds very weakly to Transportin-1. Finally, we provide evidence that FUS inclusions in FTLD-FUS contain UMA and, to a lesser extent, MMA FUS, in contrast to ALS-FUS where FUS appears to be exclusively asymmetrically dimethylated.

\section{Materials and methods}

\section{Cell lines, cell culture, transfections and inhibitor treatment}

Human cervical carcinoma cells (HeLa) were cultured in Dulbecco's Modified Eagle Medium (DMEM) supplemented with $10 \%(\mathrm{v} / \mathrm{v})$ fetal calf serum (FCS), glutamine and penicillin/streptomycin at $37{ }^{\circ} \mathrm{C}$ with $5 \% \mathrm{CO}_{2}$ in a tissue culture incubator.
Mouse embryonic stem (mES) cells, PRMT1 knockout $(-/-)$ and wild-type controls (+/+) [44], were cultured with STEMPAN GMEM (Cat. No. P08-50600, PAN Biotech) supplemented with $10 \%(\mathrm{v} / \mathrm{v})$ fetal bovine serum (PANsera Cat. No. P30-2602, PAN Biotech), penicillin/ streptomycin and leukaemia inhibitory factor (ESGRO Mouse LIF Medium Supplement, Cat. No. ESG1107, Millipore) at a final concentration of $10^{3} \mathrm{U} / \mathrm{ml}$. Adenosine- $2^{\prime}, 3^{\prime}$ dialdehyde (AdOx; Sigma) was used as a methyltransferase inhibitor [6] on HeLa cells for $48 \mathrm{~h}$ at a concentration of $20 \mu \mathrm{M}$. AdOx treatment has been used to inhibit dimethylation of proteins [6] and to increase not only the UMA but also the MMA forms [16]. FUS, EWS and TAF-15 knockdowns were achieved by using the ON-TARGET plus FUS SMARTpool L-009497, the ON-TARGET plus EWSR1 SMARTpool L-005119 and the ON-TARGET plus TAF-15 SMARTpool L-008930, respectively, all from Dharmacon. A non-targeting siRNA (ON-TARGET plus NT siRNA \#3, D-001810-03 from Dharmacon) was used as a negative control. siRNAs were delivered to cells by reversed transfection using Lipofectamine 2000 (Invitrogen) according to the manufacturer's instructions. The effect of the knockdown was assessed $48 \mathrm{~h}$ post-transfection.

\section{Generation of monoclonal antibodies and peptides}

Monoclonal antibodies were generated in LOU/C rats or C57BL/6 mice against ovalbumin-conjugated $\mathrm{FUS}_{473-503}$ peptide (RGGRGGYDRGGYRGRGGDRGGFRGGRGGGDR), corresponding to the RGG3 domain of FUS, in which all nine arginines were either unmethylated (UMA FUS) or monomethylated (MMA FUS) (Fig. 1a). The ADMA FUS antibody (9G6) was previously described and characterized [13]. Rat monoclonal antibodies were also raised against the ADMA RGG3 domain of EWS (EWS ${ }_{564-583}$ GRGGPGGMRGGRGGLMDRGG) and TAF-15 (TAF-15 $458-477$ DRGGGYGGDRGGGYGGDRGG), using ovalbumin-conjugated peptides. All antibodies were produced by standard procedures.

Peptides were synthesized by Peps4LS GmbH, or Peptide Specialty Laboratories GmbH. For the methylated peptides, modified amino acids (ADMA or MMA, respectively) were used instead of arginine during synthesis. Peptides were purified by gradient HPLC-purification on a C-18 preparative HPLC column and the single fractions were characterized by UV trace of an analytical HPLC spectrum. Only fractions with a $>90 \%$ purity were combined and confirmed by MALDI mass spectrometry.

The hybridoma supernatants were first screened by ELISA using the corresponding ADMA, MMA or UMA peptides as antigens. Next, they were assessed in immunoblotting of cell culture lysates of HeLa cells. The UMA FUS-specific clone 14G1 (Rat IgG 2a) showed the best 
performance, for MMA FUS-specificity, clone 15E11 (Rat IgG 2a) was chosen. To confirm the results obtained with these antibodies, we generated and selected an additional monoclonal UMA FUS-specific antibody, (2A3; Mouse $\operatorname{IgG} 2 b$ ), and an additional monoclonal MMA FUS-specific antibody (18E11; Rat IgG 2a). Similarly, we selected the best ADMA EWS-specific clone (21B1; Rat IgG1) and the best ADMA TAF-15-specific clone (Rat 12F11; Rat IgG 2c). All hybridomas were subcloned at least twice to ensure monoclonality and stability of the clones. Where necessary, antibodies were purified via protein $\mathrm{G}$ column.

\section{Other antibodies}

The following commercial antibodies were used: EWSspecific mouse monoclonal antibody G5 sc28327 (Santa Cruz) and rabbit polyclonal antibody H-60 sc28865 (Santa Cruz); FUS-specific mouse monoclonal antibody 4H11 (Santa Cruz) and rabbit polyclonal A300-294A (Bethyl) and HPA008784 (Sigma); HA-specific mouse monoclonal antibody HA.11 (Covance); MonomethylArginine ( $\mathrm{R}^{*} \mathrm{GG}$ )-specific rabbit monoclonal antibody D5A12 \#8711 (Cell Signalling); MonomethylArginine-specific monoclonal rabbit antibody Me-R4-100 \#8015 (Cell Signalling); PRMT1-specific rabbit monoclonal EPR3292 (Abcam); TAF-15-specific rabbit antibody TAF15-308A (Bethyl), rabbit polyclonal antibody SAB2102361 (Sigma) and mouse monoclonal antibody H00008148 (Abnova); Transportin-specific rabbit antibody clone D45 (Sigma); $\alpha$-Tubulin-specific mouse monoclonal antibody clone B-51-2 (Sigma).

The secondary antibodies for immunoblotting were horseradish peroxidase (HRP)-conjugated goat anti-mouse, anti-rabbit or anti-rat IgG (Promega) or mouse anti-rat IgG2a, IgG2b and IgG2c (home made).

\section{Protein analysis}

Total cell lysates were prepared in ice-cold RIPA buffer (50 mM Tris- $\mathrm{HCl} \mathrm{pH} 7.4,150 \mathrm{mM} \mathrm{NaCl}, 1 \% \mathrm{NP}-40$, $0.5 \%$ sodium deoxycholate, $0.1 \%$ sodium dodecyl sulphate) freshly supplemented with Protease inhibitor Cocktail (Roche), sonicated (Bioruptor from Diagenode), and their protein concentration was determined by BCA protein assay (Interchim). Lysates were then supplemented with SDS-PAGE sample buffer $(62.5 \mathrm{mM}$ Tris-HCl $\mathrm{pH}$ $6.8,2 \%$ sodium dodecylsulfate, $0.03 \%$ bromophenol blue, $143 \mathrm{mM} \beta$-mercaptoethanol, $10 \%$ glycerol) and boiled for $5 \mathrm{~min}$.

For immunoprecipitation, whole $\mathrm{mES}$ cell extracts were prepared in mild lysis buffer $(50 \mathrm{mM}$ Tris- $\mathrm{HCl} \mathrm{pH} \mathrm{8.0,}$ $150 \mathrm{mM} \mathrm{NaCl}, 2 \mathrm{mM}$ EDTA, $1 \%$ Triton X-100) for the immunoprecipitation of FUS, EWS and MMA proteins, or in RIPA buffer for the immunoprecipitation of TAF-15. The lysates were pre-cleared with washed Protein G Sepharose beads (Thermo Scientific) for $30 \mathrm{~min}$ at $4{ }^{\circ} \mathrm{C}$, followed by incubation for $2 \mathrm{~h}$ at $4{ }^{\circ} \mathrm{C}$ with the antibody of interest coupled to Protein $\mathrm{G}$ beads. The beads were washed three times with the lysis buffer and boiled in $2 \times$ SDS-PAGE sample buffer to elute bound proteins.

Proteins were separated by SDS-PAGE and transferred to PVDF membranes (Imobilon-P, Millipore). Membranes were blocked in $5 \%$ powdered milk in TBST and incubated in primary antibody overnight at $4{ }^{\circ} \mathrm{C}$. Membranes were probed with HRP-coupled secondary antibodies and developed with the chemiluminescence detection reagents ECL or ECL plus (both from Thermo Scientific).

To examine solubility of FET proteins, a sequential extraction was performed as described [11] with some modifications. Briefly, cells were washed with PBS, lysed in cold RIPA buffer and sonicated. Lysates were centrifuged at $180,000 \mathrm{~g}$ for $30 \mathrm{~min}$ at $4{ }^{\circ} \mathrm{C}$. After removal of the RIPA-soluble fraction, RIPA-insoluble pellets were washed three times with RIPA buffer, sonicated and re-pelleted. Insoluble pellets were dissolved in urea buffer $(7 \mathrm{M}$ urea, $2 \mathrm{M}$ thiourea, $4 \%$ CHAPS, $30 \mathrm{mM}$ Tris, $\mathrm{pH}$ 8.5). Both soluble and insoluble fractions were supplemented with SDSPAGE sample buffer and boiled.

\section{Neuronal culture, transfection and treatment}

Cortical neurons were prepared from embryonic day 18 Sprague-Dawley rat embryos and cultivated in Neurobasal medium (ThermoFisher) supplemented with $2 \%$ B27 (ThermoFisher), $1 \%$ penicillin/streptomycin, $0.25 \%$ glutamine and $0.125 \%$ glutamate as described previously [41]. Cells were harvested 7 days later (DIV7) in RIPA buffer. Adox $(10 \mu \mathrm{M})$ treatment was started $48 \mathrm{~h}$ prior to harvesting.

\section{In vitro pull-down assay}

In vitro pull-down assays were performed as previously described [13]. Briefly, N-terminally biotinylated UMAFUS $_{473-503}$, MMA-FUS ${ }_{473-503}$ and ADMA-FUS ${ }_{473-503}$ peptides were immobilized on streptavidin Sepharose beads (GE Healthcare) and blocked in wash buffer $(20 \mathrm{mM}$ sodium phosphate buffer $\mathrm{pH} 7.4,150 \mathrm{mM} \mathrm{KCl}, 0.5 \mathrm{mM}$ EDTA, $5 \mathrm{mM} \mathrm{MgCl} 2,10 \%$ glycerol, $1 \mathrm{mM}$ DTT) supplemented with $0.5 \mathrm{mg} / \mathrm{ml}$ BSA. The peptide-coupled beads were then incubated with increasing amounts of recombinant TRN-His ${ }_{6}$ or $\mathrm{His}_{6}-\mathrm{GST}$ for $1-3 \mathrm{~h}$ at $4{ }^{\circ} \mathrm{C}$. The beads were washed, boiled in SDS-PAGE sample buffer and eluted proteins were resolved by SDS-PAGE and visualized by staining with GelCode Blue Stain Reagent (Thermo Scientific). 


\section{Protein expression and purification}

Escherichia coli (E. coli) BL21 (DE3) cells were transformed with a modified version of the pETM11 expression vector (including a $\mathrm{His}_{6}$, protein A tag and a tobacco etch virus-TEV- protease cleavage site) harbouring the $E$. coli codon optimize gene of Transportin-1. One litre of

a

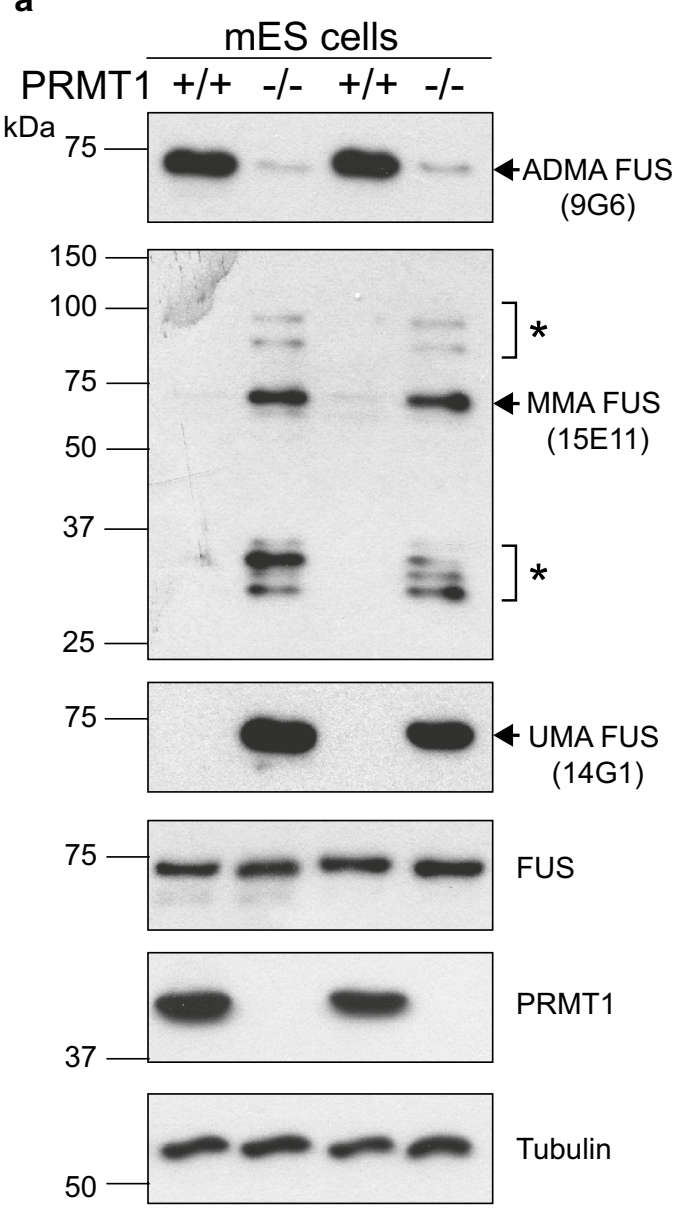

(9G6)
M9 minimal medium was inoculated, cultures were grown for 2 days at $25{ }^{\circ} \mathrm{C}$, diluted to OD 1.0 and induced with $0.5 \mathrm{mM}$ IPTG for either $6 \mathrm{~h}$ at $25^{\circ} \mathrm{C}$ or $14 \mathrm{~h}$ at $19{ }^{\circ} \mathrm{C}$. Cells were resuspended in $30 \mathrm{ml}$ purification buffer [110 mM potassium acetate, $20 \mathrm{mM}$ Hepes, $\mathrm{pH}$ 8.0, $2 \mathrm{mM}$ $\mathrm{MgCl}_{2}, 2 \mathrm{mM} \beta$-mercaptoethanol (BME), $5 \%$ (v/v) glycerol and $20 \mathrm{mM}$ Imidazole], sonicated and applied to a

b

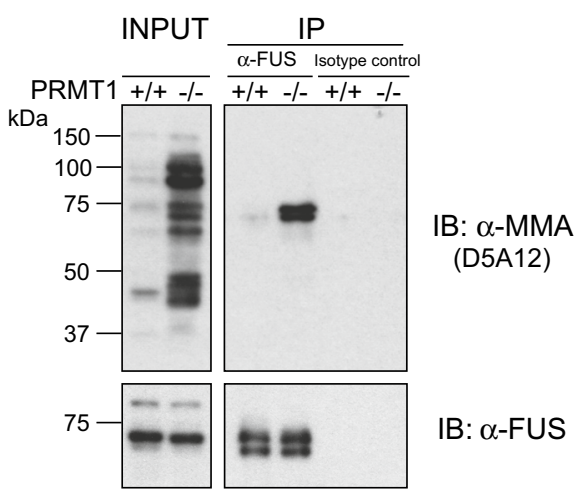

C

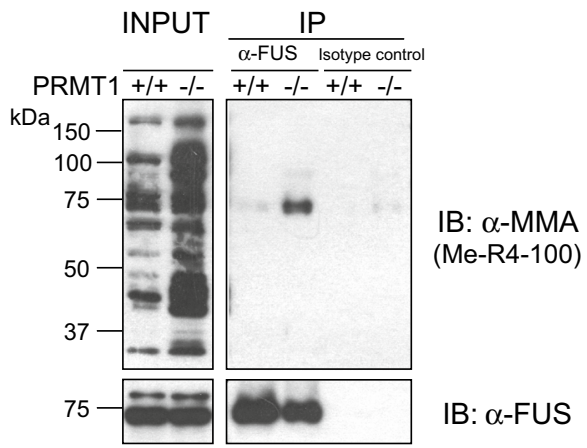

d

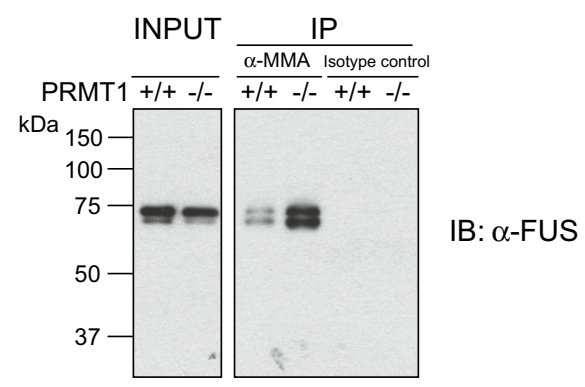

Fig. 2 Loss of PRMT1 elicits a switch in the methylation pattern of FUS from ADMA to MMA and UMA. a Whole cell lysates of PRMT1 knockout (PRMT1 -/-) and wild-type (PRMT1 +/+) mES cells (duplicates from two independent experiments) were prepared and immunoblotted with antibodies specific for ADMA FUS (9G6), MMA FUS (15E11) and UMA FUS (14G1). A decrease in ADMA FUS paralleled by an increase in UMA and MMA FUS is observed in PRMT1 -/- mES cells. Membranes were blotted with anti-Tubulin and anti-total FUS antibodies to visualize equal loading and with a PRMT1-specific antibody to confirm PRMT1 knockout. Asterisks indicate unspecific bands. b, $\mathbf{c}$ Whole cell lysates were subjected to immunoprecipitation (IP) with an anti-FUS antibody and an isotype control antibody. Precipitated proteins were analysed by immunob- lotting (IB) with a general anti-MMA antibody (D5A12) that recognizes monomethylated RGG motifs. This demonstrates an increase in MMA FUS in PRMT1 -l- cells (top panel). The input (whole cell lysates) is shown in the left panel. Equal amounts of FUS protein were immunoprecipitated from PRMT1 +/+ and PRMT1 -/cells (bottom panel). The same immunoprecipitated material was also immunoblotted with another anti-MMA antibody (Me-R4-100) raised against monomethylated arginine. This confirmed an increase in MMA FUS upon PRMT1 knockout (PRMT1 -/-). d Immunoprecipitation (IP) of monomethylated proteins followed by immunoblotting (IB) for FUS confirmed an increase of MMA FUS in PRMT1 $-/-$ cells 
Ni-NTA agarose column according to the manufacturers instruction. The protein was eluted with the same buffer including $200 \mathrm{mM}$ imidazole and further purified via size exclusion chromatography on an ÄKTA pure system equipped with HiLoad 16/600 Superdex 200 pg (for Transportin-1; column GE Healthcare) using purification buffer. The protein-containing fractions were merged and incubated with $0.2 \mathrm{mg}$ TEV protease overnight at $4{ }^{\circ} \mathrm{C}$. On the next day, the protein solution was applied on the Ni-NTA agarose column to remove the tag and the His $_{6}{ }^{-}$ tagged TEV protease. Protein was freshly prepared for ITC runs, stored at $4{ }^{\circ} \mathrm{C}$, and buffer exchanged prior the measurements on an ÄKTA pure system equipped with a HiPrep (26/10) desalting column (GE Healthcare) preequilibrated with freshly prepared ITC interaction buffer (50 mM Tris, $150 \mathrm{mM} \mathrm{NaCl}, 2 \mathrm{mM}$ tris(2-carboxyethyl) phosphine, $\mathrm{pH}$ 6.7). Protein solution was concentrated using Amicon Ultra-15 (Millipore, $3 \mathrm{kDa}$ molecular weight cut-off) centrifugal filter units to the desired concentrations.

\section{Isothermal titration calorimetry (ITC)}

Binding affinities of FUS RGG3 peptides to Transportin-1 were determined using a VP-ITC Microcal calorimeter (Microcal, Northhampton, USA) at $25{ }^{\circ} \mathrm{C}$ with a stirring speed of $300 \mathrm{rpm}$. Titrations employed an initial delay of $300 \mathrm{~s}$, a $9.6 \mu \mathrm{l}$ initial injection volume followed by $300 \mathrm{~s}$ delay, and $35 \times 19.6 \mu \mathrm{l}$ injections of FUS peptides into the Transportin-1 solution. Concentrations of Transportin- 1 were $10 \mu \mathrm{M}$ for the UMA and MMA RGG peptides and $15 \mu \mathrm{M}$ for the ADMA peptide, respectively. Concentrations of UMA RGG peptide were 100, $120 \mu \mathrm{M}$ for MMA RGG peptide and $150 \mu \mathrm{M}$ for the ADMA peptide. The ITC datasets were analysed with the program MicroCal Origin software version 7.0 assuming a single binding site.

\section{Immunohistochemistry and immunofluorescence on human post mortem tissue}

Human post mortem central nervous system (CNS) tissue was provided by the Neurobiobank Munich, LudwigMaximilians-University (Munich, Germany) and the Brain Banks affiliated with the University of Tübingen, Germany, University of British Columbia, Canada, and University of Oxford, United Kingdom. Consent for autopsy and research was obtained from the legal representative in accordance with local institutional ethical review committees.

Studied FUS-opathy cases with robust pathology in selected neuroanatomical regions included aFTLD-U $(n=4)$, BIBD $(n=2)$, NIFID $(n=3)$ and four ALS-FUS cases with three different FUS mutations, p.R521C $(n=2)$, p.P525L $(n=1)$, and p.R514S/E516 V $(n=1)$.

Immunohistochemistry was performed on $\sim 5 \mu \mathrm{m}$ thick formalin fixed paraffin embedded sections using the Ventana BenchMark XT automated staining system (Ventana, Tuscon, AZ) with the iVIEW DAB detection kit. Boiling of sections in citrate buffer ( $\mathrm{pH}$ 6) for 20 min was performed as antigen retrieval for all stainings and incubation of primary antibodies was performed overnight at $4{ }^{\circ} \mathrm{C}$. For double-label immunofluorescence, the secondary antibodies were Alexa Fluor 594 conjugated anti-rabbit and or Alexa Fluor 488 conjugated anti-rat IgG (Invitrogen, 1:500). Hoechst 33342 or DAPI was used for nuclear counterstaining. Sections were treated with Sudan black to reduce autofluorescence.

\section{Results}

\section{Generation and characterization of UMA FUS- and MMA FUS-specific antibodies}

To characterize the methylation patterns of FUS in post mortem brains of FTLD and ALS patients we developed highly selective monoclonal antibodies against the differentially

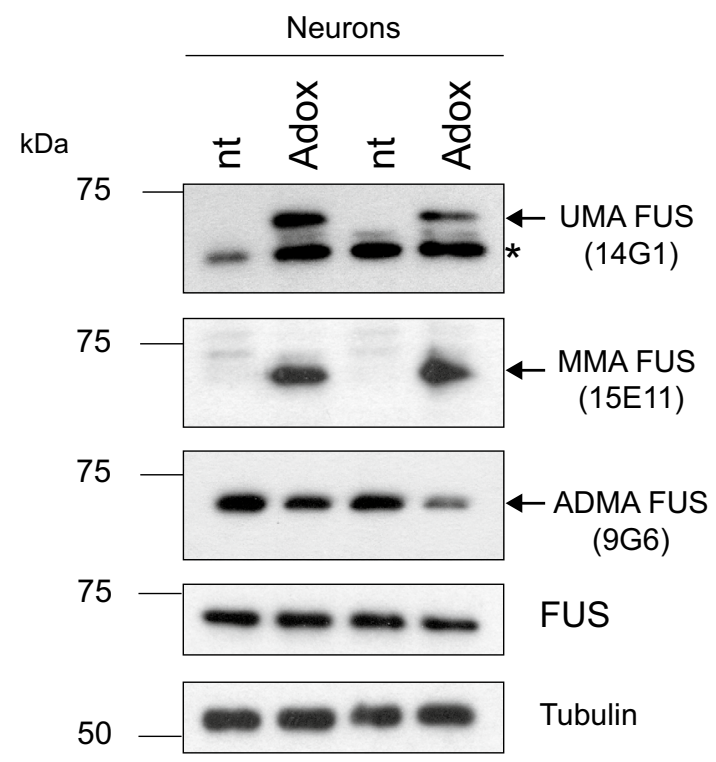

Fig. 3 Neuronal FUS switches its methylation pattern from ADMA to MMA and UMA upon treatment with AdOx. Rat cortical neurons (DIV 7) were treated with AdOx $(10 \mu \mathrm{M})$ for $48 \mathrm{~h}$ or left untreated and examined by immunoblotting with antibodies specific for UMA FUS (14G1), MMA FUS (15E11) and ADMA FUS (9G6). In line with the results observed in HeLa and mES cells, UMA FUS (14G1) and MMA FUS (15E11) were selectively increased upon treatment with AdOx, whereas ADMA FUS was decreased. Tubulin was used as a loading control. Duplicates from two independent experiments are shown. Asterisks: unspecific bands 
methylated RGG3 domain of FUS (peptide epitope FUS $_{473-}$ ${ }_{503}$; Fig. 1a). This domain is localized next to the PY-NLS and contains nine arginine residues that can be asymmetrically dimethylated [40, 46]. UMA FUS ${ }_{473-503}$ and MMA FUS $473-503$ specific antibodies were newly developed for this study, whereas the ADMA FUS-specific antibody 9G6 has been previously developed and characterized [13] (Fig. 1a). Hybridoma supernatants were screened by ELISA against all peptides, and those with a strong selective signal but no significant cross-reactivity to the other peptides were further tested by immunoblotting on HeLa cells lysates. To validate specificity, we performed siRNA-mediated FUS knockdowns and treated cells with the methylation inhibitor AdOx (adenosine$2^{\prime}-3^{\prime}$-dialdehyde). AdOx is a global methyltransferase inhibitor that reduces the ADMA of proteins [6] and conversely increases the UMA but also the MMA forms [16]. After screening a large number of antibodies, we selected an UMA FUS (clone 14G1) and MMA FUS (clone 15E11) antibody that recognized a specific band in AdOx-treated HeLa cells that was selectively absent upon knockdown of FUS but not of the other FET family members TAF15 or EWS (Fig. 1c). We also used our previously described ADMA FUS-specific antibody (clone 9G6) [13], which shows a signal in untreated cells that disappears upon treatment with AdOx or knockdown of FUS (Fig. 1c).

\section{Genetic and pharmacological reduction of PRMT1 results in a switch from asymmetrically dimethylated FUS to unmethylated and monomethylated FUS}

After having verified specificity of the UMA, MMA and ADMA FUS antibodies, we used them to investigate the

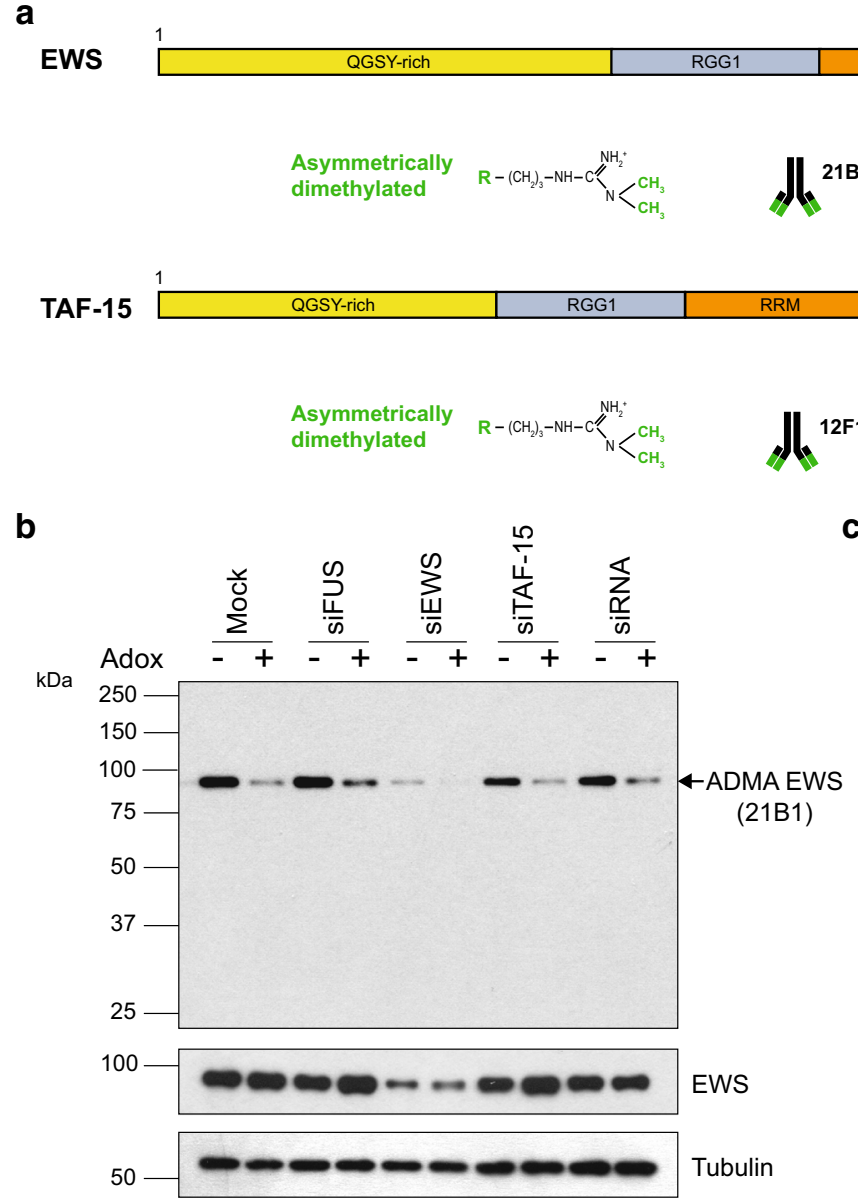

Fig. 4 Characterization of novel monoclonal antibodies specific for ADMA EWS and ADMA TAF-15. a Schematic figure of EWS and TAF-15 and their domains. Note the similarity to FUS (Fig. 1a). Antibodies were generated against the ADMA RGG3 domain of EWS and TAF15 (sequence of the peptides use for immunization indicated in the figure). b, c: siRNAs against FUS, EWS, TAF-15 or a non-targeting control were transfected into HeLa cells, and cells were either left untreated or treated with AdOx. 48 h post-transfection, lysates

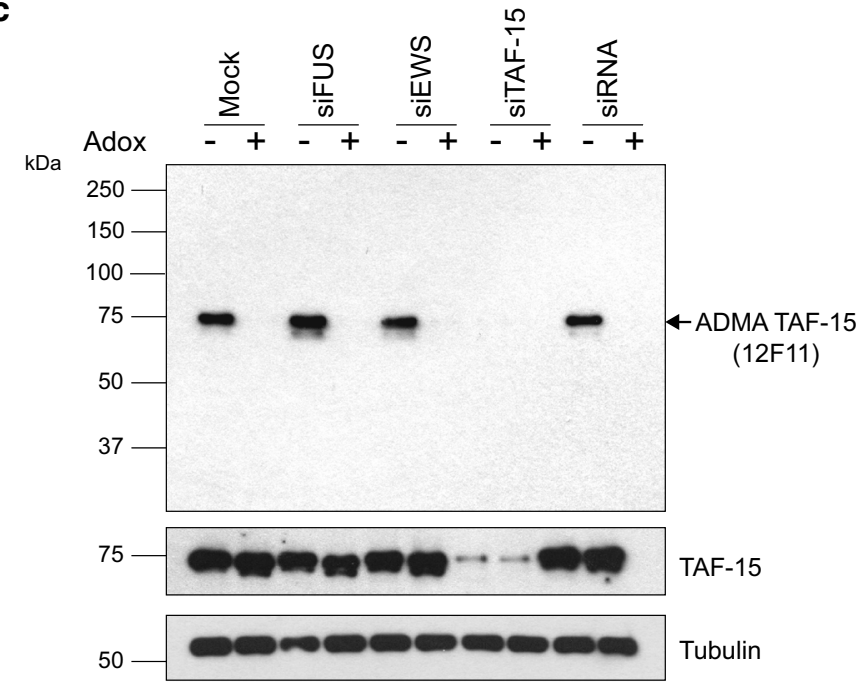

were analysed by immunobloting with the antibody raised against ADMA EWS (21B1) or TAF15 (12F11). The antibodies label one specific band at the predicted molecular weight of EWS or TAF15 (arrow) that is reduced or disappears upon knockdown of EWS or TAF15 or AdOx treatment demonstrating specificity of these antibodies for ADMA EWS and ADMA TAF-15. Tubulin was used as a loading control and EWS and TAF-15 antibodies were used to examine knockdown efficiency 
methylation status of FUS in a cellular model of hypomethylation, namely mouse embryonic stem cells (mES) that lack PRMT1 [44]. This approach allowed us to investigate how the pattern of FUS methylation changes upon loss of a major PRMT. Using our new antibodies, we observed a strong decrease in ADMA FUS and a corresponding increase of UMA FUS in PRMT1 knockout $(-/-)$ cells (Fig. 2a). The signal of ADMA FUS did not completely disappear in the PRMT1 knockout cells, indicating that, although PRMT1 is the main enzyme responsible for methylation of FUS, other PRMTs might also be involved in asymmetric dimethylation of FUS. Interestingly, upon knockout of PRMT1, there was also a significant increase of MMA FUS, as demonstrated by the increased signal with the 15E11 antibody (Fig. 2a). To further confirm this result, we performed an immunoprecipitation of FUS followed by immunoblotting with a commercially available

a

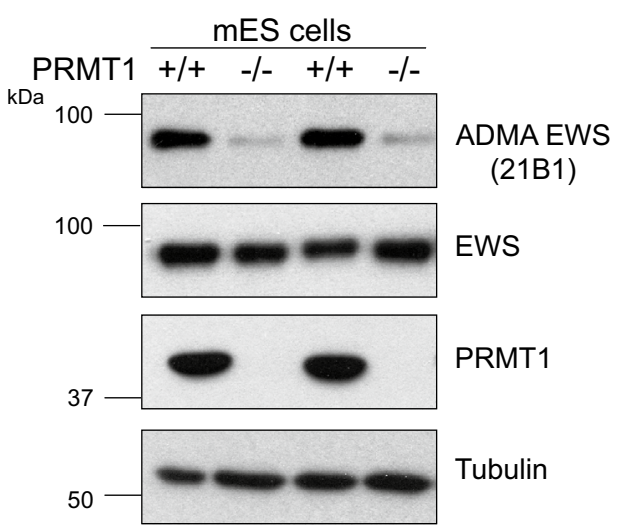

C

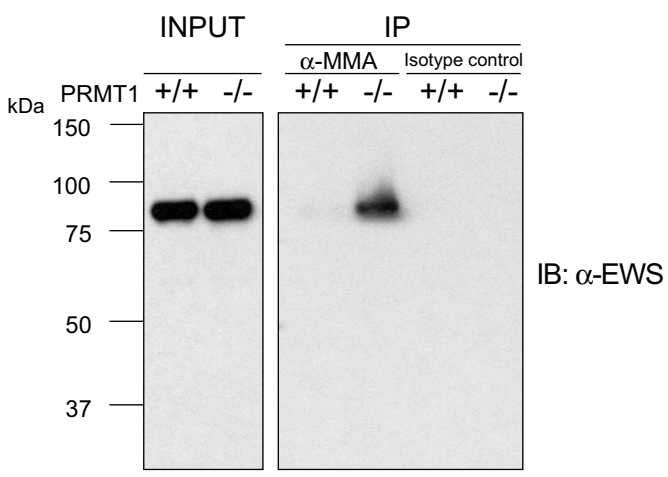

Fig. 5 Altered methylation pattern of EWS and TAF-15 upon loss of PRMT1. a Whole cell lysates of PRMT1 knockout (PRMT1 -/-) and wild-type (PRMT1 +/+) mES cells (duplicates from two independent experiments) were prepared and immunoblotted with antibodies specific for ADMA EWS (21B1). A decrease in ADMA EWS is observed in PRMT1 -/- cells. All lysates were blotted with antiTubulin and anti-total EWS antibodies to visualize equivalent loading and a PRMT1-specific antibody to verify the PRMT1 knockout.
anti-MMA antibody (D5A12), which recognizes a large number of monomethylated proteins [9]. This confirmed an increase in MMA FUS in PRMT1 knockout cells (Fig. 2b). This finding was further confirmed using another antiMMA antibody (Me-R4-100) raised against monomethylated arginine (Fig. 2c). Furthermore, the reciprocal immunoprecipitation with the anti-MMA antibody (D5A12) followed by immunoblotting for FUS also confirmed an increase in MMA FUS in PRMT1 knockout cells (Fig. 2d). Remarkably, we did not detect signals with the UMA FUS and MMA FUS-specific antibodies, even after long exposure, in both wild-type $(+/+) \mathrm{mES}$ cells (Fig. 2a) and untreated HeLa cells (Fig. 1c). Only upon enrichment after immunoprecipitation we detected a small amount of MMA FUS in wild-type mES cells (Fig. 2b-d) suggesting that under physiologic conditions these species are much less abundant than ADMA FUS.

b

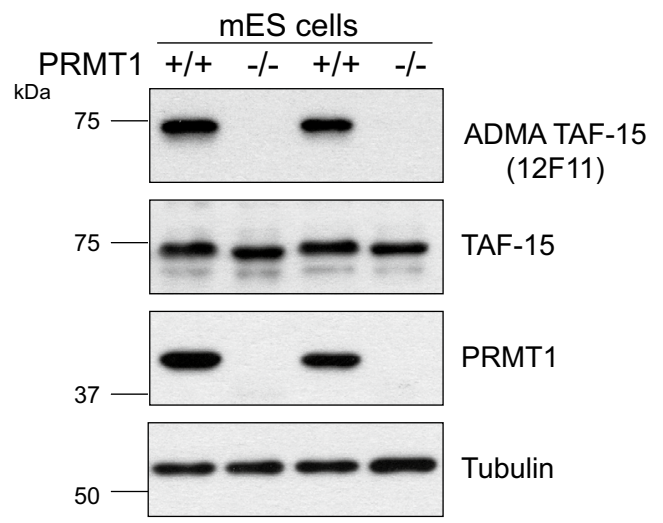

d

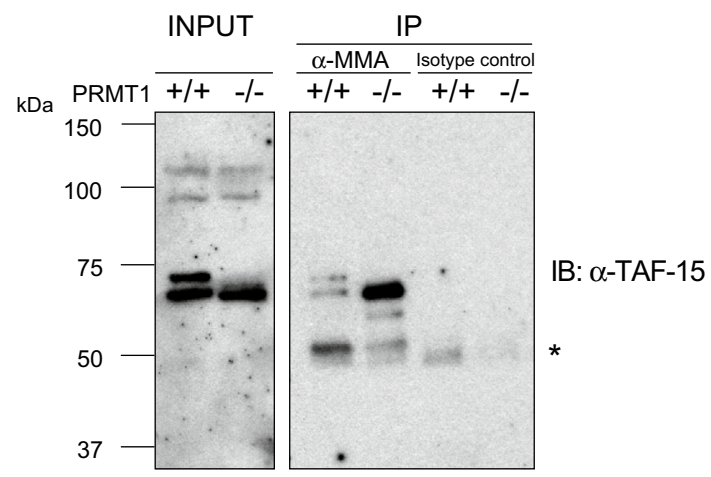

b The same lysates were immunoblotted with the ADMA TAF15 (12F11) antibody. A strong decrease in ADMA TAF-15 is observed in PRMT1 -/- cells. c, d Whole mES cell lysates were subjected to immunoprecipitation (IP) with a general anti-MMA antibody (D5A12) and an isotype control antibody. Samples were analysed by immunoblotting (IB) with an anti-EWS or anti-TAF-15 antibody. This demonstrated an increase in MMA EWS and MMA TAF-15 in PRMT1 -/- cells. Asterisk in $\mathbf{d}$ represent immunoglobulin bands 
To exclude cross-reactivity of our antibodies against other methylation patterns in PRMT1 knockout cells, we performed an antigen absorption assay with the three different peptides used for immunization (Supplementary Fig. 1a, b). The specific band recognized by the 14G1 UMA FUS antibody selectively disappeared upon preincubation of the antibody with the UMA FUS U73-503 peptide, but not with the MMA FUS $_{473-503}$ or the ADMA FUS ${ }_{473-503}$ peptide (Supplementary Fig. 1a). Likewise, the signal obtained with the 15E11 MMA FUS antibody selectively disappeared upon preincubation of the antibody with the MMA FUS ${ }_{473-503}$ peptide but not with the others (Supplementary Fig. 1b). These results confirm the selectivity of the 14G1 and 15E11 antibodies and, importantly, demonstrate the lack of crossreaction with the other methylation patterns.

To address whether a similar change in the pattern of FUS methylation also occurs in neurons, we treated rat cortical neurons with AdOx and analysed the lysates with the FUS methylation-specific antibodies. In line with our results in HeLa cells, inhibition of arginine methylation resulted in a significant and specific increase of UMA and MMA FUS (Fig. 3) demonstrating that FUS methylation is highly similar in neurons and peripheral cells.

\section{Loss of PRMT1 increases monomethylation of all members of the FET protein family, but does not affect their solubility}

Since EWS and TAF-15, the two other members of the FET protein family, have the same domain structure as
FUS and their RGG domains are known to be asymmetrically dimethylated $[1,4,21,43]$, we investigated whether they are also monomethylated upon loss of PRMT1. To do so, we generated antibodies against the ADMA RGG3 domain of EWS and TAF-15 (Fig. 4a). Again, hybridoma supernatants were screened for their specificity first by an ELISA against the peptide used for immunization and second by immunoblotting of HeLa cells lysates (Fig. 4b, c). We selected antibodies specific for ADMA EWS (clone 21B1) and ADMA TAF-15 (clone 12F11). Both detected a band at the predicted molecular weight that was reduced or selectively disappeared after treatment with AdOx or knockdown of EWS or TAF-15 (Fig. 4b, c). Using these antibodies, we observed a strong decrease in ADMA EWS and ADMA TAF-15 in PRMT1 knockout cells (Fig. 5a, b), as observed for ADMA FUS (Fig. 2a). To test whether EWS and TAF-15 also become monomethylated upon loss of PRMT1, we immunoprecipitated monomethylated proteins from whole cell lysates of wild-type or PRMT1 knockout mES cells and subsequently immunoblotted for EWS and TAF-15. Like for FUS, we observed an increase in MMA EWS and MMA TAF-15 upon knockout of PRMT1 (Fig. 5c, d). Thus, we conclude that all three FET proteins (FUS, EWS and TAF-15) are mainly asymmetrically dimethylated by PRMT1 under physiological conditions, whereas a shift towards monomethylated arginine (MMA) is observed upon loss of PRMT1.

Next, we investigated whether changes in the methylation status of FET proteins may affect their solubility. To a

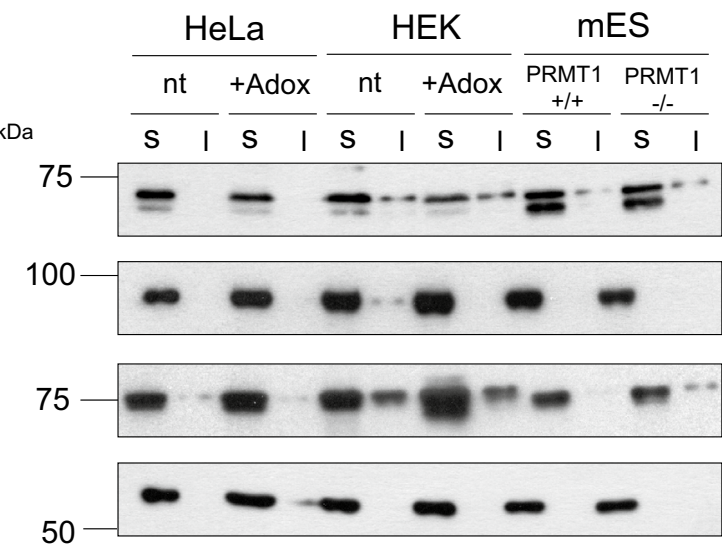

b

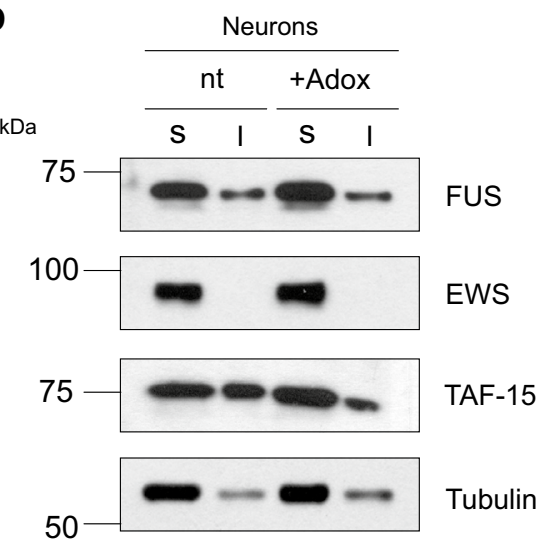

Fig. 6 Hypomethylation does not change the aggregation propensity of the FET proteins. a HeLa and HEK cells treated or untreated with AdOx and wild-type and PRMT1 knockout mES cells were fractionated in a RIPA soluble (S) and insoluble fraction (I). The insoluble fraction was dissolved in urea buffer. Immunobloting against FUS, EWS and TAF-15 shows that all FET proteins are predominantly RIPA soluble in all cells investigated. After treatment with AdOx or in PRMT1 knockout cells, the proportion of soluble and insoluble protein does not change, suggesting that hypomethylation does not affect the FET protein's aggregation propensity. b Rat cortical neurons treated or untreated with AdOx were fractionated into RIPA soluble (S) and insoluble (I) fractions. Again the proportion of soluble and insoluble protein does not change upon AdOx treatment, suggesting that hypomethylation does not affect aggregation propensity of FET proteins 
a

$$
\begin{aligned}
& \text { UMA FUS }_{473-503} \text { Biotin-RGGRGYDRGGYRGRGGDRGGFRGGRGGGDR }
\end{aligned}
$$

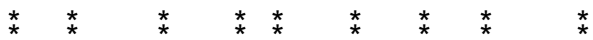

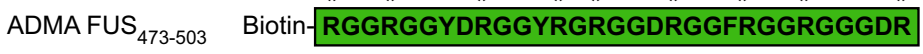

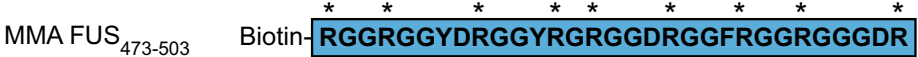

b

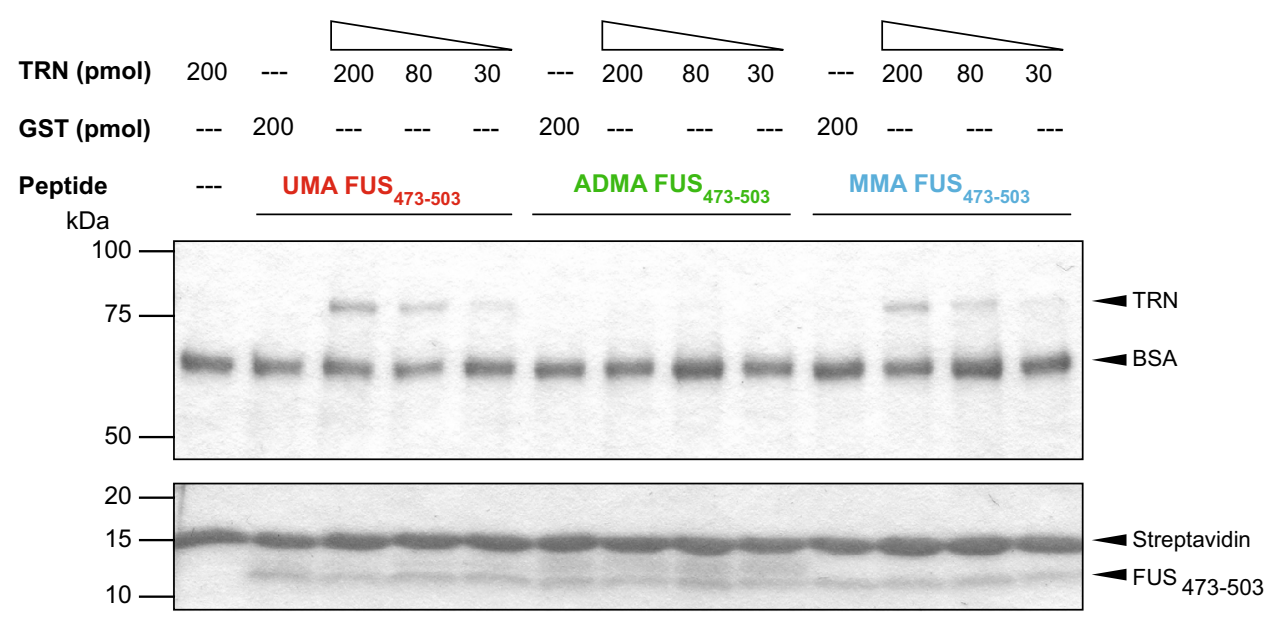

C

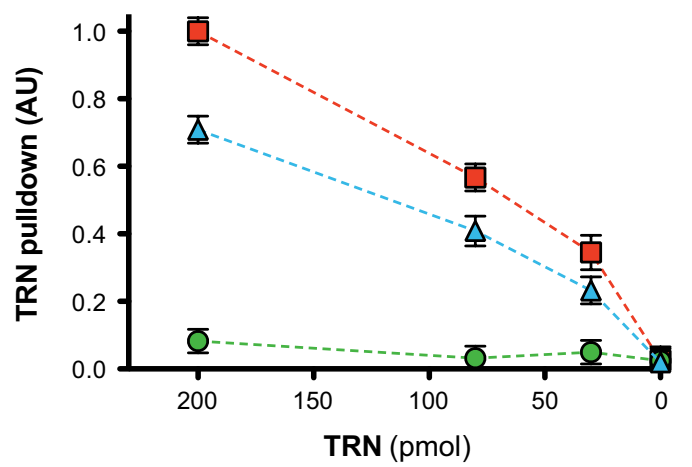

UMA FUS ${ }_{473-503}$

O. ADMA FUS ${ }_{473-503}$

$\triangle$ - MMA FUS $473-503$

Fig. 7 UMA and MMA FUS have a higher affinity to Transportin-1 (TRN) than ADMA FUS. a Schematic representation of the three different biotinylated synthetic peptides comprising the RGG3 domain of FUS (FUS ${ }_{473-503}$ ) with three different methylation patterns: UMA (red), ADMA (green) or MMA (blue). b Biotinylated FUS $_{473-503}$ peptides shown in (a) were immobilized on streptavidin beads and an in vitro pull-down assay was performed with recombinant TRN (TRN-His ${ }_{6}$ ) or $\mathrm{His}_{6}$-GST as a control. TRN bound to the

Table 1 TRN binding to FUS. dissociation constants $\left(k_{\mathrm{D}}\right)$ as determined by isothermal titration calorimetry

\begin{tabular}{lc}
\hline Sample & $k_{\mathrm{D}}(\mu \mathrm{M})$ \\
\hline UMA FUS $_{473-503}$ & $0.7 \pm 0.4$ \\
MMA FUS $_{473-503}$ & $4.5 \pm 0.9$ \\
ADMA FUS $_{473-503}$ & $12.4 \pm 10.7$ \\
\hline
\end{tabular}

FUS $_{473-503}$ peptides was visualized by SDS-PAGE and Coomassie staining (upper panel). The lower panel shows that equal amounts of streptavidin beads and $\mathrm{FUS}_{473-503}$ peptide were present in all samples. c The efficiency of the TRN pulldown was quantified by measuring the intensity of the TRN bands in the Coomassie gels of three independent pulldown experiments. The values are expressed in arbitrary units (AU) relative to the band with the highest intensity. Error bars indicate standard deviation (SD)

do so, we performed fractionation experiments in HeLa, HEK cells (untreated or treated with AdOx), mES cells (wild-type and PRMT1 knockout cells) and primary cortical neurons. After inhibition of arginine methylation none of the FET proteins shifted to the insoluble fraction in all cells investigated, including primary cortical neurons (Fig. 6a, b). These findings suggest that the methylation 
status of FET proteins does not directly affect their aggregation propensity.

\section{Unmethylated and monomethylated FUS have a higher affinity for Transportin-1}

A remarkable difference in the neuropathology of FTLDFUS and ALS-FUS is that the nuclear import receptor of the FET proteins, Transportin-1 (TRN) is present in the inclusions in FTLD-FUS but not in ALS-FUS [5, 38, 53]. Moreover, FUS is hypomethylated in FTLD-FUS cases [13]. We have previously shown that ADMA FUS has a significantly lower affinity to TRN than UMA FUS [13]. However, the affinity of MMA FUS to TRN is unknown.
Therefore, we performed in vitro pull-down assays with recombinant TRN and the three biotinylated $\mathrm{FUS}_{473-503}$ peptides (ADMA, MMA and UMA, Fig. 7a). Interestingly, both UMA and MMA FUS ${ }_{473-503}$ peptides showed a much higher affinity to TRN than ADMA FUS A73-503 (Fig. 7b, c).

To further confirm the distinct affinity of the differently methylated RGG3 FUS peptides to TRN, we performed isothermal titration calorimetry (ITC). Increasing methylation of the synthetic RGG3 peptide $\left(\mathrm{FUS}_{473-503}\right)$ resulted in increasing loss of binding affinity, corresponding to increased dissociation constants $\left(k_{\mathrm{D}}\right)$, for TRN (Table 1; Supplementary Fig. 2). This confirmed that the UMA and MMA RGG3 domains have a much higher affinity for TRN than the ADMA form.
Fig. 8 UMA FUS antibody labels inclusions in FTLD-FUS but not in ALS-FUS. Doublelabel immunofluorescence with UMA FUS antibody $14 \mathrm{G} 1$ (green), a pan-FUS antibody (red) and nuclear counterstaining with Hoechst (blue). The characteristic FUS-positive cytoplasmic and intranuclear inclusions in aFTLD-U (dentate gyrus), NIFID (dentate gyrus) and BIBD (frontal cortex) are robustly co-labelled by the UMA FUS-specific antibody, in striking contrast to the FUSpositive inclusions in ALS-FUS cases with different mutations, which are not labelled with the UMA FUS antibody. Scale bar $50 \mu \mathrm{m}$

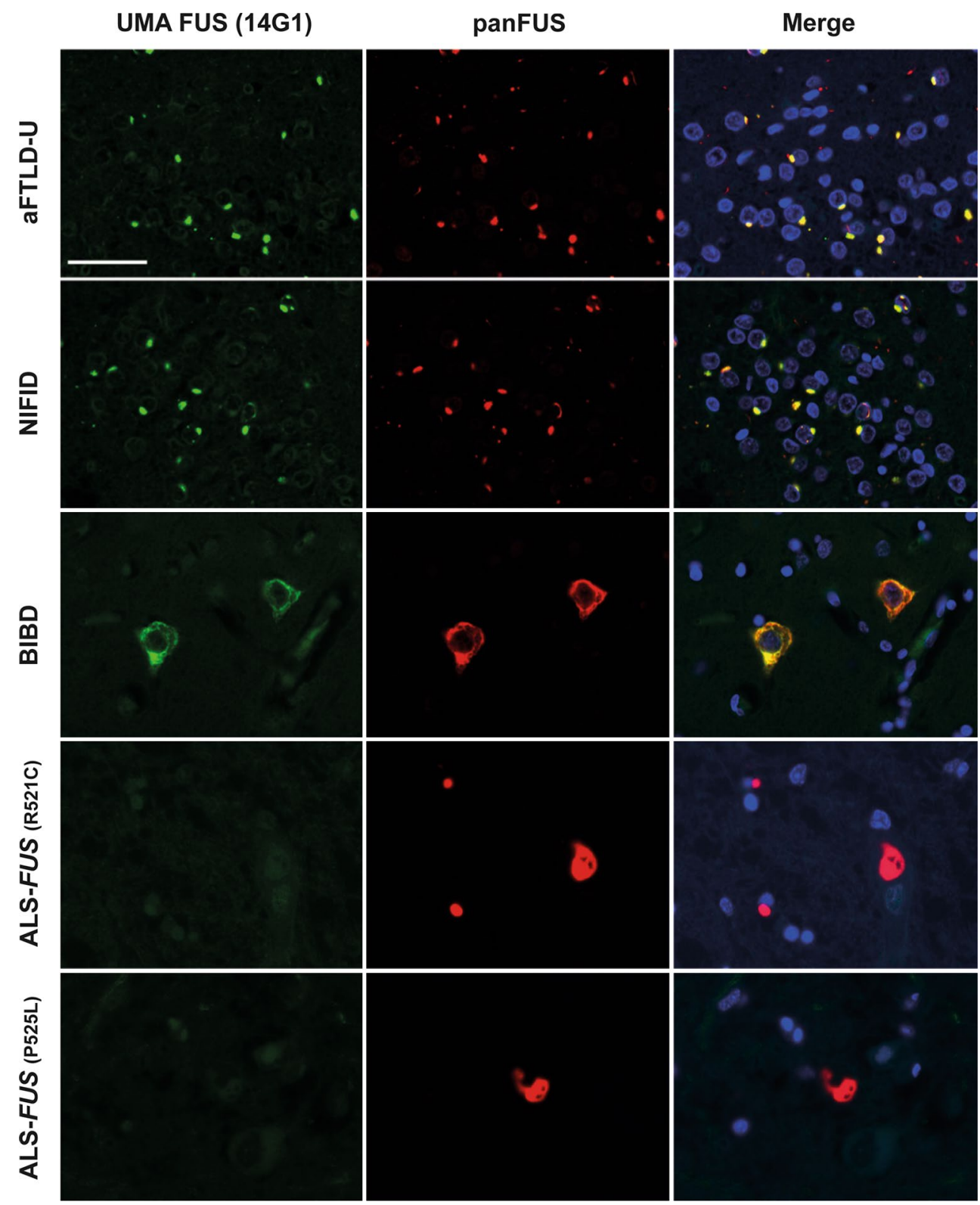




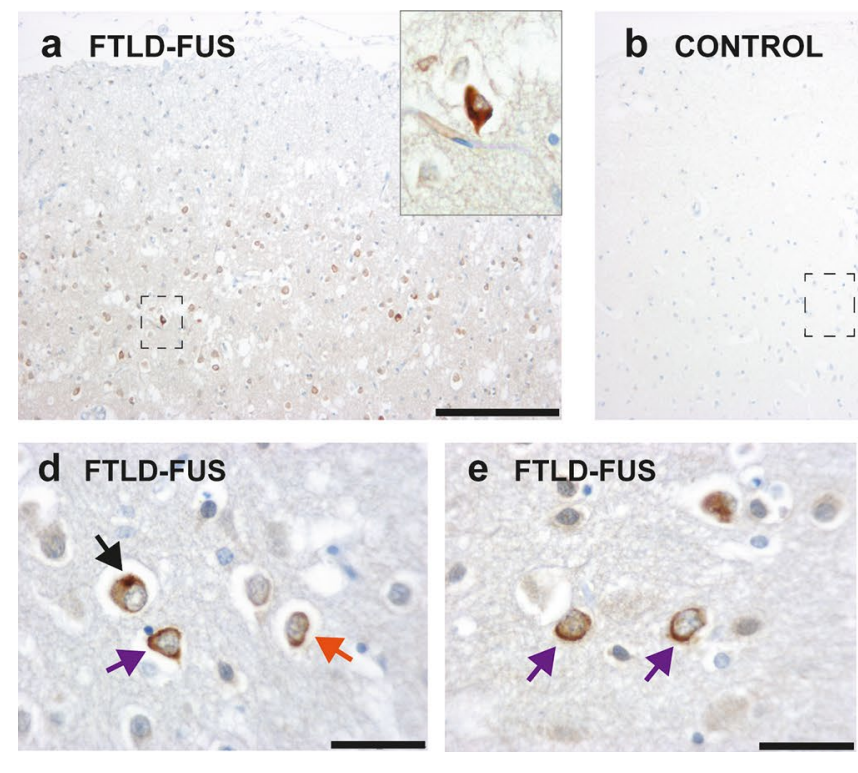

Fig. 9 UMA FUS immunohistochemistry in FTLD-FUS brains. Immunohistochemical detection of UMA FUS aggregates in the frontal cortex of a FTLD-FUS (NIFID) case using the 14G1 antibody. a In the FTLD-FUS case numerous neuronal cytoplasmic inclusions are found in the outer cortical layers (mainly layers II and III) of the superior frontal gyrus (insert represents zoomed stippled rectangle).

\section{Inclusions in FTLD-FUS but not ALS-FUS patients contain unmethylated and monomethylated FUS}

To investigate whether the observed shift in the methylation pattern of FUS towards UMA and MMA FUS that we observed in PRMT1 knockout cells (Fig. 2) also occurs in FUS-opathies, we stained human CNS tissue from ALSFUS, FTLD-FUS and controls with the antibodies specific to differentially methylated FUS. We have previously shown that FUS inclusions in all FTLD-FUS subtypes do not contain ADMA FUS, whereas inclusions in ALS-FUS cases are labelled with the ADMA FUS-specific antibody [13]. The inverse result was now seen with the UMA FUS antibody $14 \mathrm{G} 1$, which showed a robust and consistent costaining of FUS-positive cytoplasmic and intranuclear inclusions in all FTLD-FUS subtypes (Figs. 8, 9), but not in ALS-FUS (Fig. 8). No staining was observed in a control or a FTLD-TDP case, demonstrating the selectivity of the UMA FUS signal (Fig. 9). Notably, nuclei in cases and controls were not labelled with the UMA FUS-specific antibody, implying that UMA FUS is not present under physiological conditions.

Despite some background staining, the MMA FUS antibody 15E11 revealed clear labelling of a subset of FUS inclusions in all FTLD-FUS cases (Figs. 10, 11) but not in ALS-FUS (Fig. 10). Labelling of inclusions was not observed in a control or a FTLD-TDP case, also demonstrating the selectivity of the MMA FUS signal
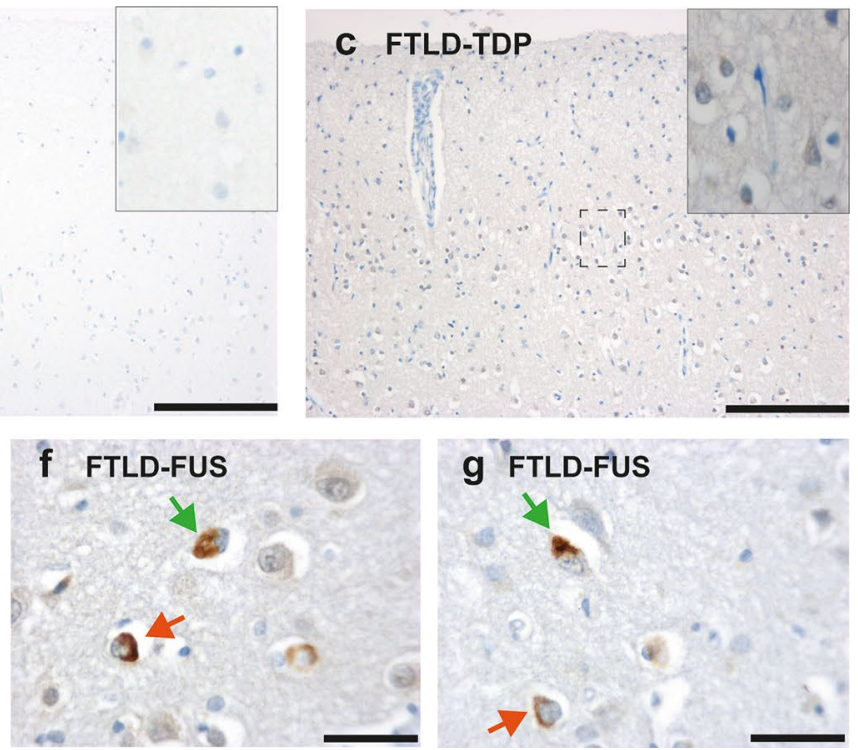

b, c UMA aggregates are not detectable in the frontal cortex of a control case or a FTLD-TDP case. d-g Shapes of cytoplasmic UMA FUS inclusions vary between ring-like (violet arrows), dot-like (black arrow), crescent (red arrows) and triangular (green arrows). Scale bars in a-c represent $200 \mu \mathrm{m}$, scale bars in $\mathbf{d}-\mathbf{g} 50 \mu \mathrm{m}$

(Fig. 11). These findings are in line with the cell culture experiments where blockage of ADMA of FUS is paralleled by the presence of MMA FUS. We confirmed these results with a second UMA FUS-specific antibody (2A3; Supplementary Fig. 3) and a second MMA FUS-specific antibody (18E11; Supplementary Fig. 4), which showed labelling of the FTLD-FUS inclusions similar to that observed by the 14G1 (UMA FUS) and 15E11 (MMA FUS) antibodies. Moreover, the UMA FUS and MMA FUS-positive inclusions co-stain with TRN, a protein specifically deposited in FTLD-FUS inclusions [5, 38, 53] (Supplementary Fig. 5).

Taken together, we demonstrate that the inclusions are clearly labelled with both the UMA FUS and the MMA FUS antibodies, which further supports our hypothesis of impaired FUS methylation regulation in FTLD-FUS pathogenesis.

\section{Discussion}

The main finding in the present study is that aggregated unmethylated and monomethylated FUS are a hallmark of FTLD-FUS. This reveals another significant difference between FTLD-FUS and ALS-FUS (Table 2) and supports the hypothesis that different mechanisms underlie the pathogenesis of both diseases, even though both disorders share FUS accumulation as a common feature. 
Fig. 10 MMA FUS antibody labels inclusions in FTLD-FUS but not in ALS-FUS. Doublelabel immunofluorescence with MMA FUS antibody 15E11 (green), a pan-FUS antibody (red) and nuclear counterstaining with Hoechst (blue). The majority of FUS-positive cytoplasmic and intranuclear inclusions in aFTLD-U (dentate gyrus), NIFID (dentate gyrus) and BIBD (frontal cortex) are co-labelled by the MMA FUSspecific antibody, in striking contrast to the FUS-positive inclusions in ALS-FUS cases with different mutations, which are not labelled with the MMA FUS antibody. Scale bar $50 \mu \mathrm{m}$

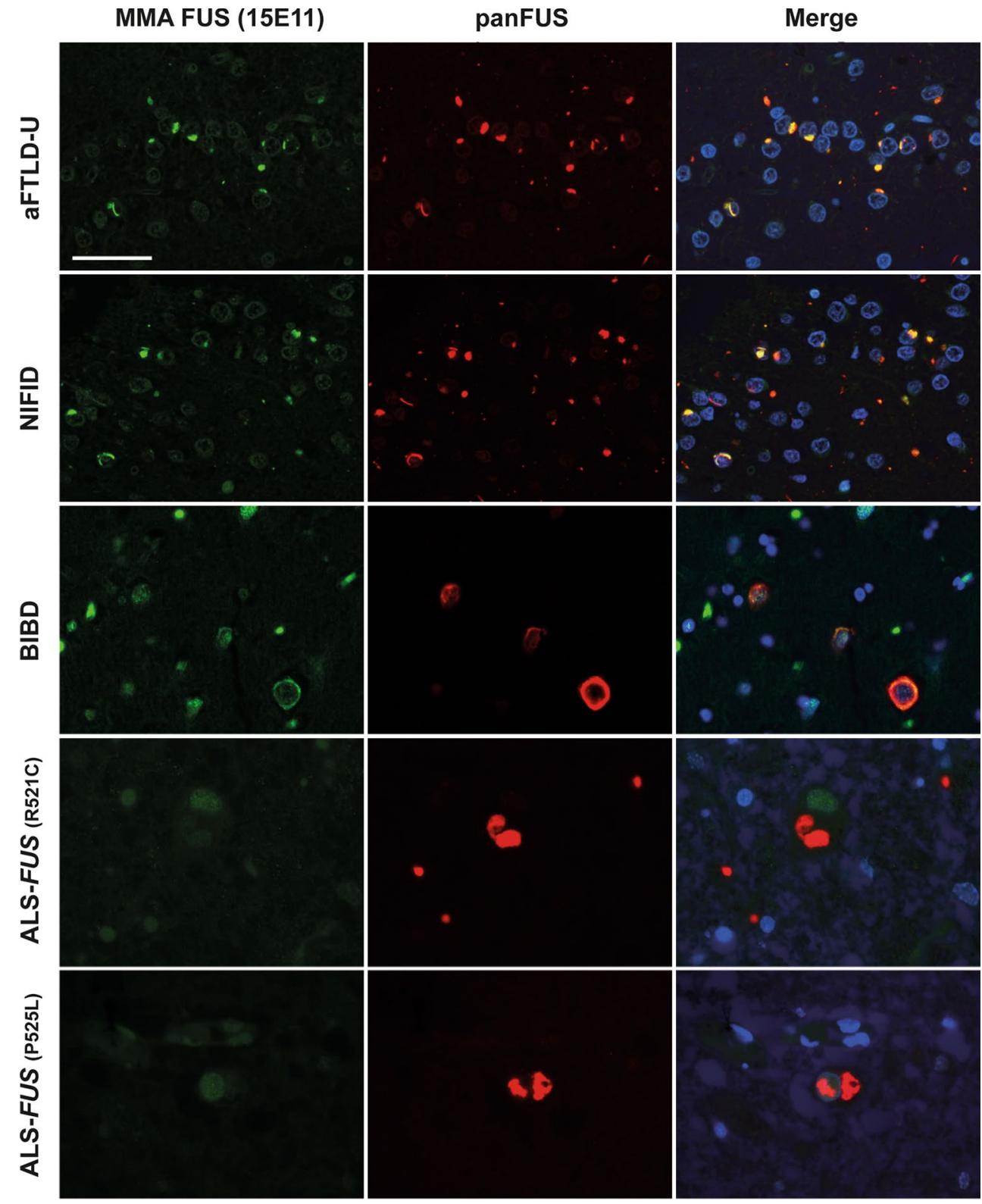

Two principal types of posttranslational modifications (PTMs) have been described for the FET proteins: arginine methylation and phosphorylation $[8,15,23,26]$. Both methylation and phosphorylation can affect the nuclearcytoplasmatic localization of FET proteins $[3,7,13,14,28$, 52] and they may also be involved in the regulation of RNA/ DNA binding, protein-protein interaction [29], stress granule recruitment [56] or the solubility of the FET proteins [42, 45, 58]. Furthermore, it has recently been described that phosphorylation of the N-terminus of FUS mediates its cytoplasmic translocation after DNA damage [8].

The hypothesis that FUS could be hypomethylated in FTLD-FUS emerged from our previous finding with an antibody specific for ADMA FUS. We could show that inclusions in ALS-FUS patients were labelled with this antibody, but inclusions in FTLD-FUS cases were not [13]. This implied that inclusions in FTLD-FUS do not contain ADMA FUS. However, the experiments did not exclude that the absent staining was caused by different conformations of FUS in inclusions in FTLD-FUS, with the epitope for our ADMA FUS antibody being inaccessible.

To model the hypomethylated state that we hypothesise to occur in FTLD-FUS, we used mES cells lacking PRMT1 [44]. Using this cellular model, we investigated how the pattern of methylation of FUS and the other FET proteins changes when FET proteins are not properly methylated by PRMT1. As expected, we observed a decrease in ADMA FUS, EWS and TAF-15 and an increase in UMA FUS upon PRMT1 knockout. Remarkably, we also observed 

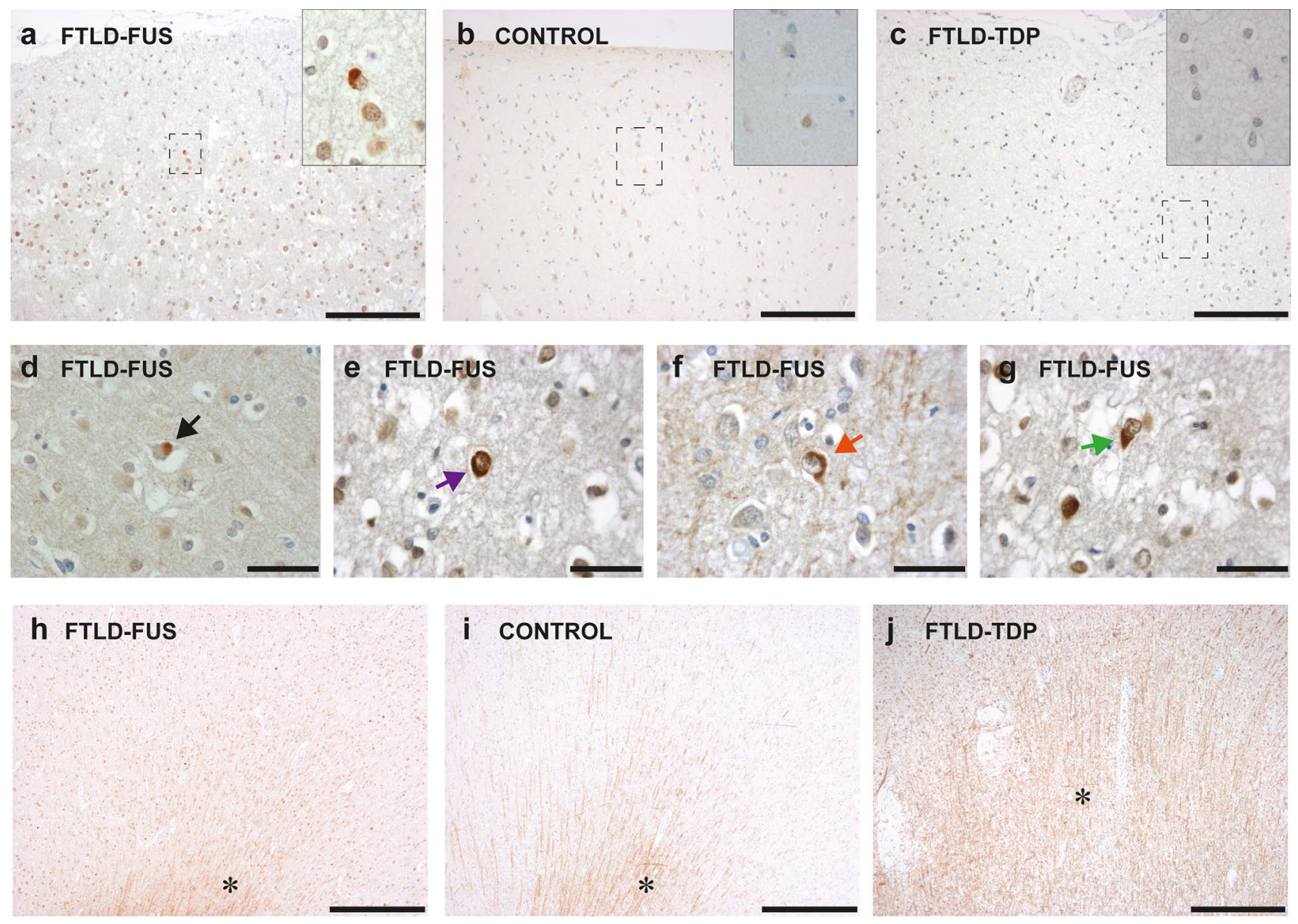

Fig. 11 MMA FUS immunohistochemistry in FTLD-FUS brains. Immunohistochemical detection of MMA FUS in the superior frontal gyrus of a FTLD-FUS (NIFID) case using the 15E11 antibody. a In the FTLD-FUS case neuronal cytoplasmic inclusions are mainly found in the outer cortical layers (layers II and III); (insert represents zoomed stippled rectangle). b, c 15E11 positive inclusions are not detectable in the frontal cortex of a control or a FTLD-TDP case. d-g As seen for UMA FUS (Fig. 9) cytoplasmic inclusions can be dot-like (black arrow), ring-like (violet arrow), crescent (red arrow)

Table 2 Comparison of FTLD-FUS and ALS-FUS pathology

\begin{tabular}{llll}
\hline & FTLD-FUS & ALS-FUS & References \\
\hline Deposition of FUS & $\checkmark$ & $\checkmark$ & {$[24,32,35,36,54]$} \\
FUS mutations & - & $\checkmark$ & {$[24,54]$} \\
$\begin{array}{l}\text { Deposition of Trans- } \\
\text { portin-1 }\end{array}$ & $\checkmark$ & - & {$[5,38,53]$} \\
Deposition of EWS & $\checkmark$ & - & {$[34]$} \\
Deposition of TAF-15 & $\checkmark$ & - & {$[34]$} \\
ADMA FUS & - & $\checkmark$ & {$[13]$} \\
MMA FUS & $\checkmark$ & - & This study \\
UMA FUS & $\checkmark$ & - & This study \\
\hline
\end{tabular}

Table modified from [12] or triangular (green arrow). There is a non-specific staining of axonal tracks in the FTLD-FUS (h), the control (i) and a FTLD-TDP case (j), which is most obvious in the subcortical white matter (asterisks in $\mathbf{h}, \mathbf{i}$ and $\mathbf{j}$ ). This background staining most likely reflects cross-reactivity with additional MMA proteins (besides MMA FUS) as shown by this antibody also in immunoblots (Fig. 1c; Fig. 2a). Scale bars in $\mathbf{a}-\mathbf{c}$, represent $200 \mu \mathrm{m}$, scale bars in $\mathbf{d}-\mathbf{g} 50 \mu \mathrm{m}$, scale bars in $\mathbf{h}-\mathbf{j}$ $500 \mu \mathrm{m}$

an increase in MMA FET proteins. Thus, all FET proteins adopt differentially methylated forms (UMA and MMA) upon loss of PRMT1 activity.

Little is known about the role of MMA as a regulator of protein function but, interestingly, several other RNA-binding proteins besides FUS can be monomethylated [16, 48], which implies that this PTM probably plays a pivotal role in RNA-binding protein regulation. Previous studies identified rare MMA sites in EWS [4, 43] and, more recently, two reports independently identified proteins that contain MMA in human cell lines through a proteomic approach $[16,48]$. Both studies applied an immunoaffinity purification of proteins containing MMA, followed by identification of these 
proteins by mass spectrometry $[16,48]$. The most common MMA-containing proteins identified were those involved in RNA processing and transcriptional regulation. Strikingly, among the MMA proteins all three FET proteins were found. Interestingly, Guo et al. [16] also describes a tissue-specific distribution of MMA proteins and report that in mouse brains most MMA proteins are involved in synaptic transmission. Whether MMA sites are merely a transition state between UMA and ADMA or indeed a distinct posttranslational modification with its own biological function is still unknown. This latter hypothesis is supported by the fact that there is a methyltransferase, PRMT7, that only catalyzes monomethylation [60]. Moreover, it has been suggested that a still uncharacterized MMA-specific demethylase may exist [48]. Monomethylation of lysines is already known to have its own biological function, namely labelling proteins for degradation through the methyl degron [27].

A still unanswered question is how the hypomethylated state may arise in brains of FTLD-FUS patients. One possible explanation would be a deficiency in PRMT activity, but this hypothesis seems unlikely, given that these enzymes methylate a broad range of substrates besides FET proteins, that are not deposited in FTLD-FUS [38]. Furthermore, no mutations in PRMT genes have been found in FTLD-FUS cases [47]. However, only three PRMTs have been investigated (PRMT1, PRMT3 and PRMT8), hence the remaining PRMTs and other genes involved in arginine methylation of FET proteins should still be considered as candidates for genetic studies in FTLD-FUS.

Despite the fact that some studies have reported that hypomethylation favours protein aggregation [42, 45, 58], our data do not support the idea that the hypomethylation of FET proteins makes them more prone to aggregate. In contrast, our present study strengthens the hypothesis that deposition of the FET proteins in FTLDFUS may be caused/favoured by the higher affinity of both UMA and MMA FUS to Transportin-1. Thus, we speculate that UMA and MMA FET proteins present in FTLD-FUS may lead to irreversible FET-Transportin-1 binding and eventually co-deposition of these proteins in cytoplasmic and intranuclear neuronal and glial inclusions. However, alternative mechanisms (such as phosphorylation of FUS) may contribute to FUS redistribution and its subsequent pathological deposition in FTLD-FUS [8].

In conclusion, this study describes the first PTM specifically associated with FTLD-FUS, namely MMA FUS. We demonstrate that MMA FUS and UMA FUS deposition are pathological hallmarks of FTLD-FUS that are not found in ALS-FUS caused by FUS mutations. This reinforces the idea that the two diseases are most likely caused by different pathomechanisms (Table 2) [12] and that loss of proper arginine methylation of the FET proteins may be involved in FTLD-FUS pathology. Furthermore, we highlight the fact that FET proteins are not only dimethylated or unmethylated, but there is a novel so far overlooked posttranslational modification of FUS (MMA FUS), whose exact biological and pathological role needs to be elucidated in the future.

Acknowledgments We thank Alice Suelzen for technical assistance. We thank H. Earl Ruley (Vanderbilt University School of Medicine; Nashville, TN, USA) for kind gift of mouse embryonic stem cells (mES) (PRMT1 knock-out and wild-type controls) and Elmar Wahle (Martin-Luther-Universität Halle-Wittenberg, Germany) for gift of reagents.

This work was supported by the European Research Council under the European Union's Seventh Framework Program (FP7/20072013)/ERC Grant Agreement No. 321366-Amyloid (advanced grant to C.H.), the Deutsche Forschungsgemeinschaft (German Research Foundation) within the framework of the Munich Cluster for Systems Neurology (EXC 1010 SyNergy D.D., C.H.) and the Emmy Noether program DO 1804/1-1 (to D.D.), and the general legacy of Mrs. Ammer (to the Ludwig-Maximilians-University/the chair of C.H.) and the German Helmholtz Association (Grant VH-VI-510 to C.H. and M.N.; Grant W2/W3-036 to M.N.). M.S. was supported by a grant from the Fondo de Investigación Sanitaria (FI09/00732), Instituto Carlos III, Madrid, Spain. T.M. was supported by the Bavarian Ministry of Sciences, Research and the Arts (Bavarian Molecular Biosystems Research Network), the German Research Foundation (Emmy Noether program MA 5703/1-1), the Centre for Integrated Protein Science Munich (CIPSM), the President's International Fellowship Initiative of CAS (No:2015VBB045), and the National Natural Science Foundation of China (No. 31450110423). We gratefully acknowledge the support of the NOMIS foundation (to M.D.R.), the Holcim Stiftung zur Föderung der wissenschaftlichen Fortbildung (to M.D.R.), and the Fondation Dufloteau (to M.D.R.).

\section{Compliances with ethical standards}

Conflict of interest The authors disclose no conflicts of interest.

\section{References}

1. Araya N, Hiraga H, Kako K, Arao Y, Kato S, Fukamizu A (2005) Transcriptional down-regulation through nuclear exclusion of EWS methylated by PRMT1. Biochem Biophys Res Commun 329:653-660. doi:10.1016/j.bbrc.2005.02.018

2. Bedford MT, Clarke SG (2009) Protein arginine methylation in mammals: who, what, and why. Mol Cell 33:1-13. doi:10.1016/j. molcel.2008.12.013

3. Belyanskaya LL, Delattre O, Gehring H (2003) Expression and subcellular localization of Ewing sarcoma (EWS) protein is affected by the methylation process. Exp Cell Res 288:374-381

4. Belyanskaya LL, Gehrig PM, Gehring H (2001) Exposure on cell surface and extensive arginine methylation of Ewing Sarcoma (EWS) protein. J Biol Chem 276:18681-18687. doi:10.1074/jbc. M011446200

5. Brelstaff J, Lashley T, Holton JL, Lees AJ, Rossor MN, Bandopadhyay R, Revesz T (2011) Transportin1: a marker of FTLD-FUS. Acta Neuropathol 122:591-600. doi:10.1007/ s00401-011-0863-6 
6. Chen DH, Wu KT, Hung CJ, Hsieh M, Li C (2004) Effects of adenosine dialdehyde treatment on in vitro and in vivo stable protein methylation in HeLa cells. J Biochem 136:371-376. doi:10.1093/jb/mvh131

7. Chook YM, Süel KE (2011) Nuclear import by karyopherin- $\beta$ s: recognition and inhibition. Biochim Biophys Acta 1813:15931606. doi:10.1016/j.bbamcr.2010.10.014

8. Deng Q, Holler CJ, Taylor G, Hudson KF, Watkins W, Gearing M, Ito D, Murray ME, Dickson DW, Seyfried NT, Kukar T (2014) FUS is phosphorylated by DNA-PK and accumulates in the cytoplasm after DNA damage. J Neurosci 34:7802-7813. doi:10.1523/jneurosci.0172-14.2014

9. Dhar S, Vemulapalli V, Patananan AN, Huang GL, Di Lorenzo A, Richard S, Comb MJ, Guo A, Clarke SG, Bedford MT (2013) Loss of the major Type I arginine methyltransferase PRMT1 causes substrate scavenging by other PRMTs. Sci Rep 3:1311. doi:10.1038/srep01311

10. Dickson DW (2001) Neuropathology of Pick's disease. Neurology $56: \mathrm{S} 16-\mathrm{S} 20$

11. Dormann D, Capell A, Carlson AM, Shankaran SS, Rodde R, Neumann M, Kremmer E, Matsuwaki T, Yamanouchi K, Nishihara M, Haass C (2009) Proteolytic processing of TAR DNA binding protein- 43 by caspases produces $\mathrm{C}$-terminal fragments with disease defining properties independent of progranulin. J Neurochem 110:1082-1094. doi:10.1111/j.1471-4159.2009.06211.x

12. Dormann D, Haass C (2013) Fused in sarcoma (FUS): an oncogene goes awry in neurodegeneration. Mol Cell Neurosci 56:475-486. doi:10.1016/j.mcn.2013.03.006

13. Dormann D, Madl T, Valori CF, Bentmann E, Tahirovic S, AbouAjram C, Kremmer E, Ansorge O, Mackenzie IR, Neumann M, Haass C (2012) Arginine methylation next to the PY-NLS modulates Transportin binding and nuclear import of FUS. EMBO J 31:4258-4275. doi:10.1038/emboj.2012.261

14. Dormann D, Rodde R, Edbauer D, Bentmann E, Fischer I, Hruscha A, Than ME, Mackenzie IR, Capell A, Schmid B, Neumann M, Haass C (2010) ALS-associated fused in sarcoma (FUS) mutations disrupt Transportin-mediated nuclear import. EMBO J 29:2841-2857. doi:10.1038/emboj.2010.143

15. Gardiner M, Toth R, Vandermoere F, Morrice NA, Rouse J (2008) Identification and characterization of FUS/TLS as a new target of ATM. Biochem J 415:297-307. doi:10.1042/BJ20081135

16. Guo A, Gu H, Zhou J, Mulhern D, Wang Y, Lee KA, Yang V, Aguiar M, Kornhauser J, Jia X, Ren J, Beausoleil SA, Silva JC, Vemulapalli V, Bedford MT, Comb MJ (2014) Immunoaffinity enrichment and mass spectrometry analysis of protein methylation. Mol Cell Proteomics 13:372-387. doi:10.1074/mcp. O113.027870

17. Holm IE, Englund E, Mackenzie IR, Johannsen P, Isaacs AM (2007) A reassessment of the neuropathology of frontotemporal dementia linked to chromosome 3. J Neuropathol Exp Neurol 66:884-891. doi:10.1097/nen.0b013e3181567f02

18. Holm IE, Isaacs AM, Mackenzie IR (2009) Absence of FUS-immunoreactive pathology in frontotemporal dementia linked to chromosome 3 (FTD-3) caused by mutation in the CHMP2B gene. Acta Neuropathol 118:719-720. doi:10.1007/ s00401-009-0593-1

19. Hung CJ, Lee YJ, Chen DH, Li C (2009) Proteomic analysis of methylarginine-containing proteins in HeLa cells by two-dimensional gel electrophoresis and immunoblotting with a methylarginine-specific antibody. Protein J 28:139-147. doi:10.1007/ s10930-009-9174-3

20. Ito D, Seki M, Tsunoda Y, Uchiyama H, Suzuki N (2011) Nuclear transport impairment of amyotrophic lateral sclerosis-linked mutations in FUS/TLS. Ann Neurol 69:152-162. doi:10.1002/ana.22246

21. Jobert L, Argentini M, Tora L (2009) PRMT1 mediated methylation of TAF15 is required for its positive gene regulatory function. Exp Cell Res 315:1273-1286. doi:10.1016/j. yexcr.2008.12.008

22. Kino Y, Washizu C, Aquilanti E, Okuno M, Kurosawa M, Yamada M, Doi H, Nukina N (2011) Intracellular localization and splicing regulation of FUS/TLS are variably affected by amyotrophic lateral sclerosis-linked mutations. Nucleic Acids Res 39:2781-2798. doi:10.1093/nar/gkq1162

23. Klevernic IV, Morton S, Davis RJ, Cohen P (2009) Phosphorylation of Ewing's sarcoma protein (EWS) and EWS-Fli1 in response to DNA damage. Biochem J 418:625-634. doi:10.1042/ BJ20082097

24. Kwiatkowski TJ, Bosco DA, Leclerc AL, Tamrazian E, Vanderburg CR, Russ C, Davis A, Gilchrist J, Kasarskis EJ, Munsat T, Valdmanis P, Rouleau GA, Hosler BA, Cortelli P, de Jong PJ, Yoshinaga Y, Haines JL, Pericak-Vance MA, Yan J, Ticozzi N, Siddique T, McKenna-Yasek D, Sapp PC, Horvitz HR, Landers JE, Brown RH (2009) Mutations in the FUS/TLS gene on chromosome 16 cause familial amyotrophic lateral sclerosis. Science 323:1205-1208. doi:10.1126/science.1166066

25. Van Langenhove T, van der Zee J, Sleegers K, Engelborghs S, Vandenberghe R, Gijselinck I, Van den Broeck M, Mattheijssens M, Peeters K, De Deyn PP, Cruts M, Van Broeckhoven C (2010) Genetic contribution of FUS to frontotemporal lobar degeneration. Neurology 74:366-371. doi:10.1212/WNL.0b013e3181ccc732

26. Lee HJ, Kim S, Pelletier J, Kim J (2004) Stimulation of hTAFII68 (NTD)-mediated transactivation by v-Src. FEBS Lett 564:188-198. doi:10.1016/S0014-5793(04)00314-X

27. Lee JM, Lee JS, Kim H, Kim K, Park H, Kim JY, Lee SH, Kim IS, Kim J, Lee M, Chung CH, Seo SB, Yoon JB, Ko E, Noh DY, Kim KI, Kim KK, Baek SH (2012) EZH2 generates a methyl degron that is recognized by the DCAF1/DDB1/CUL4 E3 ubiquitin ligase complex. Mol Cell 48:572-586. doi:10.1016/j. molcel.2012.09.004

28. Leemann-Zakaryan RP, Pahlich S, Grossenbacher D, Gehring $\mathrm{H}$ (2011) Tyrosine phosphorylation in the C-terminal nuclear localization and retention signal (C-NLS) of the EWS protein. Sarcoma 2011:218483. doi:10.1155/2011/218483

29. Liu Q, Dreyfuss G (1995) In vivo and in vitro arginine methylation of RNA-binding proteins. Mol Cell Biol 15:2800-2808

30. Mackenzie IR, Neumann M, Bigio EH, Cairns NJ, Alafuzoff I, Kril J, Kovacs GG, Ghetti B, Halliday G, Holm IE, Ince PG, Kamphorst W, Revesz T, Rozemuller AJ, Kumar-Singh S, Akiyama H, Baborie A, Spina S, Dickson DW, Trojanowski JQ, Mann DM (2010) Nomenclature and nosology for neuropathologic subtypes of frontotemporal lobar degeneration: an update. Acta Neuropathol 119:1-4. doi:10.1007/s00401-009-0612-2

31. Mackenzie IR, Rademakers R, Neumann M (2010) TDP43 and FUS in amyotrophic lateral sclerosis and frontotemporal dementia. Lancet Neurol 9:995-1007. doi:10.1016/ S1474-4422(10)70195-2

32. Munoz DG, Neumann M, Kusaka H, Yokota O, Ishihara K, Terada S, Kuroda S, Mackenzie IR (2009) FUS pathology in basophilic inclusion body disease. Acta Neuropathol 118:617627. doi:10.1007/s00401-009-0598-9

33. Neary D, Snowden JS, Gustafson L, Passant U, Stuss D, Black S, Freedman M, Kertesz A, Robert PH, Albert M, Boone K, Miller BL, Cummings J, Benson DF (1998) Frontotemporal lobar degeneration: a consensus on clinical diagnostic criteria. Neurology 51:1546-1554

34. Neumann M, Bentmann E, Dormann D, Jawaid A, DeJesusHernandez M, Ansorge O, Roeber S, Kretzschmar HA, Munoz DG, Kusaka H, Yokota O, Ang LC, Bilbao J, Rademakers R, Haass C, Mackenzie IR (2011) FET proteins TAF15 and EWS are selective markers that distinguish FTLD with FUS pathology from amyotrophic lateral sclerosis with FUS mutations. Brain 134:2595-2609. doi:10.1093/brain/awr201 
35. Neumann M, Rademakers R, Roeber S, Baker M, Kretzschmar HA, Mackenzie IR (2009) A new subtype of frontotemporal lobar degeneration with FUS pathology. Brain 132:2922-2931. doi:10.1093/brain/awp214

36. Neumann M, Roeber S, Kretzschmar HA, Rademakers R, Baker M, Mackenzie IR (2009) Abundant FUS-immunoreactive pathology in neuronal intermediate filament inclusion disease. Acta Neuropathol 118:605-616. doi:10.1007/s00401-009-0581-5

37. Neumann M, Sampathu DM, Kwong LK, Truax AC, Micsenyi MC, Chou TT, Bruce J, Schuck T, Grossman M, Clark CM, McCluskey LF, Miller BL, Masliah E, Mackenzie IR, Feldman H, Feiden W, Kretzschmar HA, Trojanowski JQ, Lee VM (2006) Ubiquitinated TDP-43 in frontotemporal lobar degeneration and amyotrophic lateral sclerosis. Science 314:130-133. doi:10.1126/science. 1134108

38. Neumann M, Valori CF, Ansorge O, Kretzschmar HA, Munoz DG, Kusaka H, Yokota O, Ishihara K, Ang LC, Bilbao JM, Mackenzie IR (2012) Transportin 1 accumulates specifically with FET proteins but no other transportin cargos in FTLD-FUS and is absent in FUS inclusions in ALS with FUS mutations. Acta Neuropathol 124:705-716. doi:10.1007/s00401-012-1020-6

39. Niu C, Zhang J, Gao F, Yang L, Jia M, Zhu H, Gong W (2012) FUS-NLS/Transportin 1 complex structure provides insights into the nuclear targeting mechanism of FUS and the implications in ALS. PLoS One 7:e47056. doi:10.1371/journal.pone.0047056

40. Ong SE, Mittler G, Mann M (2004) Identifying and quantifying in vivo methylation sites by heavy methyl SILAC. Nat Methods 1:119-126. doi:10.1038/nmeth715

41. Orozco D, Tahirovic S, Rentzsch K, Schwenk BM, Haass C, Edbauer D (2012) Loss of fused in sarcoma (FUS) promotes pathological Tau splicing. EMBO Rep 13:759-764. doi:10.1038/ embor.2012.90

42. Ostareck-Lederer A, Ostareck DH, Rucknagel KP, Schierhorn A, Moritz B, Huttelmaier S, Flach N, Handoko L, Wahle E (2006) Asymmetric arginine dimethylation of heterogeneous nuclear ribonucleoprotein $\mathrm{K}$ by protein-arginine methyltransferase 1 inhibits its interaction with c-Src. J Biol Chem 281:1111511125. doi:10.1074/jbc.M513053200

43. Pahlich S, Bschir K, Chiavi C, Belyanskaya L, Gehring H (2005) Different methylation characteristics of protein arginine methyltransferase 1 and 3 toward the Ewing Sarcoma protein and a peptide. Proteins 61:164-175. doi:10.1002/prot.20579

44. Pawlak MR, Scherer CA, Chen J, Roshon MJ, Ruley HE (2000) Arginine $N$-methyltransferase 1 is required for early postimplantation mouse development, but cells deficient in the enzyme are viable. Mol Cell Biol 20:4859-4869. doi:10.1128/ MCB.20.13.4859-4869.2000

45. Perreault A, Lemieux C, Bachand F (2007) Regulation of the nuclear poly(A)-binding protein by arginine methylation in fission yeast. J Biol Chem 282:7552-7562. doi:10.1074/jbc. M610512200

46. Rappsilber J, Friesen WJ, Paushkin S, Dreyfuss G, Mann M (2003) Detection of arginine dimethylated peptides by parallel precursor ion scanning mass spectrometry in positive ion mode. Anal Chem 75:3107-3114

47. Ravenscroft TA, Baker MC, Rutherford NJ, Neumann M, Mackenzie IR, Josephs KA, Boeve BF, Petersen R, Halliday GM, Kril J, van Swieten JC, Seeley WW, Dickson DW, Rademakers R (2013) Mutations in protein $N$-arginine methyltransferases are not the cause of FTLD-FUS. Neurobiol Aging 34:2235.e112235.e13. doi:10.1016/j.neurobiolaging.2013.04.004
48. Sylvestersen KB, Horn H, Jungmichel S, Jensen LJ, Nielsen ML (2014) Proteomic analysis of arginine methylation sites in human cells reveals dynamic regulation during transcriptional arrest. Mol Cell Proteomics 13:2072-2088. doi:10.1074/mcp. O113.032748

49. Talbot K, Ansorge O (2006) Recent advances in the genetics of amyotrophic lateral sclerosis and frontotemporal dementia: common pathways in neurodegenerative disease. Hum Mol Genet 15:R182-R187. doi:10.1093/hmg/ddl202

50. Tang J, Frankel A, Cook RJ, Kim S, Paik K, Williams KR, Clarke S, Herschman HR (2000) PRMT1 is the predominant type I protein arginine methyltransferase in mammalian cells. $\mathrm{J}$ Biol Chem 275:7723-7730

51. Thandapani P, O'Connor TR, Bailey TL, Richard S (2013) Defining the RGG/RG motif. Mol Cell 50:613-623. doi:10.1016/j. molcel.2013.05.021

52. Tradewell ML, Yu Z, Tibshirani M, Boulanger MC, Durham HD, Richard S (2012) Arginine methylation by PRMT1 regulates nuclear-cytoplasmic localization and toxicity of FUS/TLS harbouring ALS-linked mutations. Hum Mol Genet 21:136-149. doi:10.1093/hmg/ddr448

53. Troakes C, Hortobágyi T, Vance C, Al-Sarraj S, Rogelj B, Shaw CE (2013) Transportin 1 colocalization with Fused in Sarcoma (FUS) inclusions is not characteristic for amyotrophic lateral sclerosis-FUS confirming disrupted nuclear import of mutant FUS and distinguishing it from frontotemporal lobar degeneration with FUS inclusi. Neuropathol Appl Neurobiol 39:553-561. doi:10.1111/j.1365-2990.2012.01300.x

54. Vance C, Rogelj B, Hortobágyi T, De Vos KJ, Nishimura AL, Sreedharan J, Hu X, Smith B, Ruddy D, Wright P, Ganesalingam J, Williams KL, Tripathi V, Al-Saraj S, Al-Chalabi A, Leigh PN, Blair IP, Nicholson G, de Belleroche J, Gallo JM, Miller CC, Shaw CE (2009) Mutations in FUS, an RNA processing protein, cause familial amyotrophic lateral sclerosis type 6. Science 323:1208-1211. doi:10.1126/science. 1165942

55. Vance C, Scotter EL, Nishimura AL, Troakes C, Mitchell JC, Kathe C, Urwin H, Manser C, Miller CC, Hortobágyi T, Dragunow M, Rogelj B, Shaw CE (2013) ALS mutant FUS disrupts nuclear localization and sequesters wild-type FUS within cytoplasmic stress granules. Hum Mol Genet 22:2676-2688. doi:10.1093/hmg/ddt117

56. Yamaguchi A, Kitajo K (2012) The effect of PRMT1-mediated arginine methylation on the subcellular localization, stress granules, and detergent-insoluble aggregates of FUS/TLS. PLoS One 7:e49267. doi:10.1371/journal.pone.0049267

57. Yang Y, Bedford MT (2013) Protein arginine methyltransferases and cancer. Nat Rev Cancer 13:37-50. doi:10.1038/nrc3409

58. Yu MC, Bachand F, McBride AE, Komili S, Casolari JM, Silver PA (2004) Arginine methyltransferase affects interactions and recruitment of mRNA processing and export factors. Genes Dev 18:2024-2035. doi:10.1101/gad.1223204

59. Zhang ZC, Chook YM (2012) Structural and energetic basis of ALS-causing mutations in the atypical proline-tyrosine nuclear localization signal of the Fused in Sarcoma protein (FUS). Proc Natl Acad Sci 109:12017-12021. doi:10.1073/pnas.1207247109

60. Zurita-Lopez CI, Sandberg T, Kelly R, Clarke SG (2012) Human protein arginine methyltransferase 7 (PRMT7) is a type III enzyme forming $\omega$-NG-monomethylated arginine residues. J Biol Chem 287:7859-7870. doi:10.1074/jbc.M111.336271 